\title{
Review Article \\ The Determination of Arsenic Compounds: A Critical Review
}

\author{
Julian Tyson \\ Department of Chemistry, University of Massachusetts Amherst, Amherst, MA 01003, USA \\ Correspondence should be addressed to Julian Tyson; tyson@chem.umass.edu
}

Received 29 November 2012; Accepted 17 December 2012

Academic Editors: A. Bouklouze, P. Campíns-Falcó, and A. Troiani

Copyright (C) 2013 Julian Tyson. This is an open access article distributed under the Creative Commons Attribution License, which permits unrestricted use, distribution, and reproduction in any medium, provided the original work is properly cited.

\begin{abstract}
A large number of publications describe the determination of arsenic in "environmental" samples in the broadest sense, a substantial subset of which focus on plant-based foodstuffs. There is a considerable interest in the inorganic arsenic content of food, especially rice, as there is recent evidence that concentrations may be high enough to exceed acceptable risk thresholds. The methodology for the determination of arsenic in rice is critically evaluated and results (a) for a rice flour reference material (National Institute of Standards SRM 1568a, certified only for total arsenic) and (b) a recent proficiency test (run by the European Commission's Joint Research Centre Institute for Reference Materials and Measurement) are examined. Difficulties with this particular analysis may lie in the sample preparation stages, over which there is still disagreement with regard to species stability, though a simple, hotwater extraction may be sufficient. High performance liquid chromatography separations with plasma-source mass spectrometry detection are popular; however, chromatographic separations are often not adequately described, the enhancement effect of carboncontaining species is often overlooked, and the fate of chlorine-containing species, responsible for an isobaric overlap interference, often obscure. Compound-dependent responses, for which there is a plenty of evidence, are almost never acknowledged or discussed.
\end{abstract}

\section{Introduction}

Writing reviews of some aspect of the measurement of arsenic compounds as described in the burgeoning literature is a popular activity. The field is too large to be encompassed by any one review article, and so the authors of each recent review have defined a subsample of the literature on which to focus; however, there is significant overlap, as several writers have chosen the topic of the measurement of arsenic compounds in environmental samples. In the paper that you are reading right now, the focus will be on an evaluation of the current status of our ability to measure one or more defined arsenic compounds of interest in a variety of materials, but with some emphasis on foodstuffs and a particular emphasis on rice. And to simplify matters even more, particular attention will be given to procedures in which the arsenic compounds are separated by high performance liquid chromatography (HPLC) and detected and quantified by inductively coupled plasma mass spectrometry (ICP-MS). A further restriction of a 5 -year time horizon (approximately) has also been imposed.
As will be discussed below, there is currently considerable interest in the arsenic content of rice (it may be high enough to be a health hazard), and there is quite recent evidence that the analytical chemistry community cannot get satisfactory results for the measurement of the relevant compounds in rice, even when the homogeneity and stability of the sample are not factors affecting the results.

Many areas of scientific study, research, and practice depend on the availability of information about the chemical composition of relevant materials. This kind of information is also vital to many manufacturing industries, as the chemical composition of raw materials, intermediates, final products, and wastes almost certainly impacts decisions about the various manufacturing processes that affect the financial "bottom line." While the general public may not have ever had any formal education in the role that chemical measurements play in ensuring the quality of their lives, many citizens of western countries assume that information about the chemical composition of their blood can be reliably determined and transmitted to their doctor; they also assume that it is safe to 
eat the food they buy and a high proportion of them will also assume that it is safe to drink the water that comes out of the tap in their homes.

The practice of chemical analysis, therefore, consists of providing information about the chemical composition of relevant materials that is useful to the end-user of the information-"useful" in the sense that it can be the basis on which to take a decision. At the same time, the end-user, who is almost certainly operating under time and financial constraints, wants the information in a reasonable time and at a reasonable cost. As the quality of the information provided is a function of the amount of time and money devoted to obtaining the information, some sort of dialogue is needed to ensure that the needs of the end user in terms of the cost effectiveness of the information are being met. In turn, this means that the quality of the information provided is less that the best possible. If this dialogue is to be meaningful, then everyone who needs information about chemical composition should have an appreciation of the scope and limitations of chemical measurement methodology and technology, which in turn means having an understanding of the some of the basic principles and concepts of chemical measurement science.

A major driving force for chemical analysis research and development is the needs of the end-user for information that is of better quality in terms of a wide variety of criteria, including detection capability, accuracy, precision, speed, cost, and multideterminand capability. The outcomes of chemical analysis research and development are made available in the relevant literature, and, therefore, the needs of many scientific disciplines can be assessed by examining the publications in the analytical chemistry literature. Scientists currently have unprecedented access to the world's scientific literature and quite complex searches can be implemented with a few keystrokes and clicks of the mouse.

\section{Arsenic}

The Web of Science database of 50.2 million journal articles dating back to 1889 contains 4,000 articles whose titles contain variations on the search terms "arsen*" and either "anal " or "determin"." Unfortunately the distinction between "analysis" and "determination" appears to have been lost, and the titles of journal articles regularly feature them as though they were synonyms, which is not so: samples are analyzed, and analytes are determined. Sorting these chronologically, as shown in Figure 1, reveals that the rate of publication has been increasing, though this is probably true for almost every other determination of any given analyte in the various matrices of interest. A more general search of the world's literature for journal articles with some variant of "arsen" " in the title shows that in recent years that has been a steady increase in the numbers of publications dealing with transport and transformations of arsenic compounds in the environment, and, in particular, the extent to which arsenic compounds are getting into drinking water and food.

These topics have formed the basis of a number of recent (past five years) books [1-3], which could be taken as a sign that there is sustained interest in the topics. Although

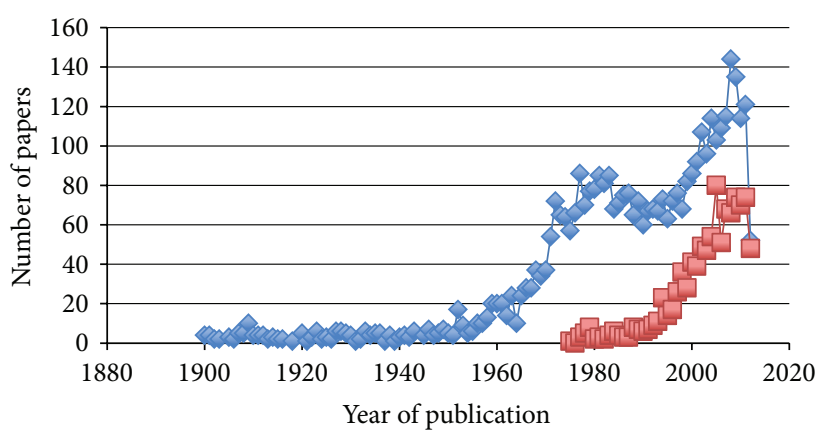

FIGURE 1: Plots of (blue) number of papers published each year dealing with the determination or arsenic, and (red) numbers of papers dealing with speciation of arsenic compounds, as a function of time.

published in 2005, Professor Andrew Meharg's Venomous Earth [4] an account of the interaction of the various life forms on our planet with a variety of arsenic-containing chemicals, written for a general readership, is a good starting point. Also written for a general readership and highly readable is Professor William Cullen's 2008 book [5] with the provocative title Is Arsenic an Aphrodisiac? and (unlike Venomous Earth) all Cullen's sources are cited and there is an extensive, 20-page index.

2.1. Arsenic in the Environment. It is clear from the contents of these recent books that it is the need to gain a deep understanding of the sources, fate, transport, and transformations of arsenic compounds in the natural environment that is providing significant driving force for the development of suitable analytical chemistry methodology. As textbooks represent a tertiary level of interaction with the literature, there is, of course, an associated secondary level of review articles. There have also been several special issues of specialist journals devoted to aspects of the environmental and analytical chemistry of arsenic compounds.

About 10 years ago, the journal Talanta devoted an entire issue (January 2002) to the "arsenic situation" [6]. The 235page issue contains (a) 15 articles describing some aspect of the analytical chemistry of arsenic compounds, (b) an account of the plight of the residents of many areas of the Indian subcontinent who are drinking arsenic-contaminated ground water, and (c) a review [7] entitled "Arsenic round the world." This review article has been cited more than 700 times (at the time of writing), but unfortunately contains errors in the opening paragraph that have not been pointed out. The authors write that arsenic ranks 20th in the earth's crust, 14th in seawater, and 12th in the human body, but the reality is that arsenic ranks somewhere between 46th and 54th in the earth's crust $[8,9]$, between 24th and 28th in seawater [8-10], and is about 31st in the human body [10]. The rest of the article is a satisfactory account of (a) the occurrence of arsenic compounds due to natural and anthropogenic processes, (b) 48 accidental arsenic poisoning incidents ( 23 from groundwater, 19 from industrial activity, and 6 from food), and (c) metabolism and toxicity, including an account of 17 different effects on various internal and 
external organs. Deliberate poisonings are not included, apart from reminding readers that one theory concerning the death of Napoleon Bonaparte involves arsenical poisoning. There is, in fact, considerable controversy over the cause of his death, a topic largely outside the scope of reviews of the analytical chemistry of arsenic, unless one is particularly interested in the analysis of hair. Cullen [11] summarizes the evidence up to about 2007 and concludes that the hair analyses "seem to indicate" that Napoleon was "exposed to arsenic in some form while he was on St. Helena and Elba." On the other hand, there is considerable weight of expert scientific opinion in favor of the "stomach cancer" explanation [12].

In 2008, volume 197 of the journal Reviews of Environmental Contamination [13] contained six articles concerned with the issues of arsenic contamination of drinking water under the heading "Arsenic Pollution and Remediation: An International Perspective." The issue also includes an index to the contents of the articles. One of the reviews [14] deals with arsenic pollution sources, both natural and anthropogenic inputs to the environment, but the impact on food is not within the scope of the review, though we do learn that in the Guizhou Province of China, chili peppers smoked over high-arsenic coal contained as much as $70,000 \mu \mathrm{g} \mathrm{kg}^{-1}$ of arsenic and several thousand individuals were adversely affected. Only one of the six articles is concerned with some analytical chemistry issues, but the focus is on field portable test kits, an interesting area with some challenges for modern measurement technologies, but outside the scope of the current review.

In 2009, volume 31 of the journal Environmental Geochemistry and Health [15] was devoted to the subject of "Arsenic in the Environment-Risks and Management Strategies." The special issue contained 3 review articles and 17 original papers. The three review articles covered (a) the extent of arsenic contamination in southeast Asia [16], (b) human exposure and risk assessment at the landscape level [17], and (c) chronic exposure from drinking water and the adverse health impacts [18]. Only three of the original papers were of significant analytical chemistry interest: two were concerned with the extraction of arsenic species, in one case from soils [19], and in the other from spinach [20]. The importance of the extraction stage of an overall analytical method will be discussed below. The third original paper was concerned with field test kits.

Although not all of the arsenic compounds that we are likely to ingest have their origin in the deliberate distribution into the environment, many of the more high profile exposure routes can be traced back to an activity in which arseniccontaining compounds were used because of their ability to kill unwanted living organisms. Many parts of the US contain exposed timber structures that have been treated with a solution of chromic oxide, copper oxide, and arsenic pentoxide in water. After squeezing the mixture in under pressure and drying, the resulting material, known as CCA (chromated copper arsenate) pressure-treated wood, is highly resistant to attack by wood boring insects, and the fungi that "rot" wood. It has been estimated [21] that $70 \%$ of singlefamily homes in the US have a deck or porch made from CCA-treated wood and many communities had children's play structures made from the material. As a result of public pressure (exerted through the media), the US EPA worked with the timber preservation industry so that, by the end of 2003, CCA-treated wood was no longer available for domestic uses. It is still used for utility poles, marine pilings, plywood flooring, shingles, and highway sound barriers, to name just a few of the "nondomestic" uses of the material. Many communities have replaced their CCA-wooden play structures even though the risk of developing cancer as a result of exposure to the arsenic (eating arsenic-rich particles coming from the surface of the wood) has been estimated as between 1 in 500,000 and 1 in 10,000 [22], a risk that the EPA considers acceptable [23].

It was not until 1988 that lead arsenate was officially banned as a pesticide in the US, although global usage had peaked as long ago as 1944. It was initially used to combat the damage inflicted by the codling moth on the production of apples and other fruit. As lead arsenate is insoluble, elevated concentrations of lead and arsenic are readily found in soils today [24], though there is no evidence that the residues in the soil are available to plants. Lead arsenate was also used to combat the boll weevil's devastation of the US cotton production, but was replaced by the sodium salts (mono and di) of monomethylarsonate and by dimethylarsinic acid (also known as cacodylic acid). These compounds, which are water soluble, were applied to control weed growth as well the weevil infestation. However, the introduction of genetically modified cotton resistant to the broad-spectrum herbicide glyphosate meant that the arsenicals were no longer needed and, since 1997, their usage in cotton production has declined significantly. To add to the arsenic burden of the cotton fields, arsenic acid was sprayed to kill the plant by desiccation prior to mechanical harvesting. Land that was once used for cotton production in the US is now used for rice production, and it has been suggested that the high concentrations of dimethylarsinate found in US rice are due to the remobilization of cacodylic acid residues still in the soil [25]. While there is clear evidence that the prior application of arsenic herbicides and pesticides affects the growth of rice (in particular the compounds induce a condition known as "straighthead" disease), the evidence of the impact on the arsenic speciation in the grain is mostly circumstantial. One study [26], however, shows that prior application of monomethylarsonate to the soil produced elevated concentrations of total arsenic in rice grain (as high as $1,500 \mu \mathrm{g} \mathrm{kg}^{-1}$ ).

2.2. Are We at Risk from Arsenic in Food? While the issues and discussions about the contamination of drinking water with arsenic compounds have been ongoing for 30 years, an awareness of the risks associated with arsenic compounds in foodstuffs is more recent. The first paper indicating that rice (and flour, grape juice, and cooked spinach) contained sufficiently high concentrations of inorganic arsenic for them to be described as "significant contributors to dietary intake" in the US [27] appeared only in 1999. By then it was well known that not all arsenic compounds found in food are equally toxic, and thus the measurement of the total arsenic content of a foodstuff did not necessarily indicate anything about the potential health hazard. Seafood (fish and shellfish), 
which contains the highest concentrations of total arsenic (up to $6,000 \mu \mathrm{g} \mathrm{kg}^{-1}$ wet weight), may contain almost undetectable (say less than $1 \mu \mathrm{g} \mathrm{kg}^{-1}$ wet weight) concentrations of inorganic arsenic. All of the arsenic is present in the forms of arsenobetaine and arsenocholine, which are considered to be nontoxic. In the early two thousands, the extent of the contamination of the world's rice supply with inorganic arsenic started to become apparent as more measurements were made and the results published. By 2012, the world's literature on the topic of "arsenic and rice" had grown to over 310 journal articles and one book [28]. From which it is clear that the foodstuffs with by far the highest concentrations of inorganic and dimethylated arsenic compounds are rice and rice products. It is also clear that the entire world's rice supply is more or less contaminated [28].

In early 2010, the European Food Safety Authority (EFSA) released a 199-page report [29] entitled "Scientific Opinion on Arsenic in Food" being the results of deliberations by the EFSA Panel on Contaminants in the Food Chain. Not only did the panel review the data submitted by 15 European countries for the total arsenic content of 100,000 food items, but they also modeled the dose-response data from several key epidemiological studies as well as noting what other epidemiologists had concluded. They used the response of $1 \%$ extra risk (of several cancers) as the "benchmark" and calculated that the dose producing this response ranged from 0.3 to $8 \mu \mathrm{g}$ per kg body weight per day. They also calculated that people consumed, on average, between 0.13 and $0.56 \mu \mathrm{g}$ per kg body weight per day of inorganic arsenic (rising to 0.37 to $1.2 \mu \mathrm{g}$ per kg body weight per day for the $95 \%$ percentile), and they concluded that the exposure for children under three years of age was between 2- and 3- times higher than that of adults. Of the eight recommendations, four concerned analytical methodology.

(1) There is a need to produce speciation data for different food commodities (to refine risk assessment of inorganic arsenic by supporting dietary exposure assessment and dose-response data for the possible health effects).

(2) Although several arsenic speciation methods have been reported, their suitability for a range of food samples and/or arsenic species needs to be established.

(3) There is a need for robust validated analytical methods for determining inorganic arsenic in a range of food items.

(4) Certified reference materials, especially for inorganic arsenic, in products such as water, rice, and seafood are required. The production of such a material should be a priority to facilitate the future surveys of the inorganic arsenic content of foods.

In the US, the situation regarding exposure to arsenic in the diet has been modeled based on the information in a number of databases related to eating patterns together with data on the total and inorganic content of foods measured by Schoof et al. [27]. They selected 40 commodities that were predicted to account for $90 \%$ of the dietary inorganic arsenic intake in the US and measured total arsenic as well as the arsenite, DMA and MMA contents, with the arsenate being calculated by difference. If appropriate, foods were cooked before analysis. They found that rice had, by far, the highest concentration of inorganic arsenic. Meacher et al. [30] estimated the inorganic arsenic intake by the US population from several sources and concluded that exposure was highest from food, then from water and those from soil and air-borne particulates were negligible. They calculated that the intake was between 1.8 and $11 \mu \mathrm{g}$ per day (10th to 90th percentiles) with females ingesting about $75 \%$ as much. As the average US adult weighs $191 \mathrm{lb}(\mathrm{m})$ and $164 \mathrm{lb}(\mathrm{f})$, the intake ranges from 0.02 to $0.13 \mu \mathrm{g}$ per $\mathrm{kg}$ bw per day. Xue et al. [31] concluded in 2010 (again based on modeling and the Schoof et al. measurements) that for adults aged 20 to 49 the range of intakes of inorganic arsenic was from 0 to $0.11 \mu \mathrm{g}$ per kg bw per day (5th to 95th percentiles). They also concluded (a) that this intake from food for this section of the population was the same as that from water and that the foods contributing most to the inorganic arsenic intake were vegetables; fruits and fruit juices; rice; beer and wine; flour, corn, and wheat, in that order. The order, presumably, reflects the eating patterns of the average American. It also reflects the accuracy of the data in the report by Schoof et al., which in the light of more recent analysis of the inorganic arsenic content of rice [32] is suspect. Schoof et al. only examined four samples, finding that the inorganic arsenic accounted for only between 16 and $49 \%$ with an average of $24 \%$ and were unable to account for over $80 \%$ of the arsenic in one sample and over $40 \%$ of the arsenic in another two, even though they looked for all of the species now known to account of all of the arsenic in rice. A recent survey of rice (and rice products) on supermarket shelves in the US [33] shows that the percentage of inorganic arsenic can be as high as 80. Also they found inorganic arsenic concentrations to be between 55 and $97 \mu \mathrm{g} \mathrm{kg}^{-1}$, whereas many of the products surveyed recently had much higher values (up to $200 \mu \mathrm{g} \mathrm{kg}^{-1}$ ).

Clearly, quite a lot is known about the total arsenic and inorganic arsenic contents of several foodstuffs, but to answer the question as to whether we are at risk from the ingestion of the inorganic arsenic in our food, it is necessary to define what is meant by "at risk." Although this is a topic that is outside the theme of this review article, it bears some examination, as, unless the answer is "yes," a major driving force for the continued development of methods for analysis of foodstuffs diminishes significantly. The EFSA panel [29] has highlighted a response of $1 \%$ extra risk (of cancer over the course of a lifetime) as the "benchmark." Their interpretation of the epidemiological data produces a range of values for the $95 \%$ lower confidence limit of this benchmark of 0.3 to $8 \mu \mathrm{g}$ per kg bw per day. They also conclude that it is not appropriate to identify a dose with "no appreciable health risk," and so the concept of a tolerable daily (or weekly) intake is not valid. This latter conclusion was also reached by the Joint FAO/WHO Expert Committee on Food Additives [34] who withdrew the previous provisional tolerable weekly intake number and replaced it with a benchmark dose corresponding to $0.5 \%$ increased incidence of lung cancer, the lower limit of which 
was $3 \mu \mathrm{g}$ per kg bw per day. The US EPA's upper target risk (of cancer over a lifetime) is 1 in 10,000 [23], a response which corresponds to a dose of $0.027 \mu \mathrm{g}$ per kg bw per day on the basis of a slope of 3.67 per mg per kg bw per day [23].

These US and European definitions of "safe" or "acceptable" differ by two orders of magnitude. Assuming that the dose-response curve is linear, the EFSA dose for a 1 in 10,000 risk would range from 0.003 to $0.08 \mu \mathrm{g}$ per $\mathrm{kg}$ bw per day, a range that includes the EPA's value of 0.027. If the response of an excess lifetime risk of cancer of 1 in 10,000 is taken as the basis for what is "safe," an $80-\mathrm{kg}$ adult should not consume more than anything from 0.24 to $6.4 \mu \mathrm{g}$ of inorganic arsenic per day. According to the Consumer Reports November 2012 results of the analysis of 233 samples of packaged, uncooked rice, and rice-containing foods and beverages purchased in the New York metropolitan area and online [33], a recommended serving of any rice or rice product would deliver an amount of inorganic arsenic within this range. Although the EFSA does not use the term "unsafe," the report does indicate that even at a 100-fold less stringent definition of safe, the estimated dietary exposures to inorganic arsenic for average and high-level consumers in Europe are with the range of the benchmark values and therefore there is little or no margin of error and "the possibility of a risk to some consumers cannot be excluded."

The Consumer Reports [33] article, as well as making suggestions for how much of a particular rice product to eat (per day or per week), called on the US FDA to set a standard for arsenic in food and in rice in particular. A suggestion that the FDA is taking seriously as the agency has already (at the time of writing) released an initial set of results for inorganic arsenic in about 200 products [35]; it "will analyze these results and determine whether or not to issue additional recommendations."

Clearly there is an ongoing role for chemical analysis, as any standards that are to be meaningful must be supported by reliable information about the chemical composition. Given that most seafood contains high concentrations of innocuous arsenic-containing compounds (arsenobetaine and arsenocholine and possibly a range of arsenosugars), it is likely (a) that different standards will be needed for different food groups, and (b) standards will be based on species of arsenic rather than on total arsenic, at least for some food groups. While the situation for seafood is relatively clear a standard should be based on the inorganic content [36], the situation for rice is complicated by the fact that in many rice products a considerable fraction of the arsenic is present as dimethylarsinate (DMA), or, more rarely, monomethylarsonate (MMA). The toxicity of these methylated compounds is uncertain. In a late 2011 article, Gilbert-Diamond et al. [37] wrote, "although inorganic arsenic is thought to be more harmful than DMA, further epidemiological studies are needed to better understand the health risks of DMA." The issue had already been raised by Heitkemper et al. [38] who wrote in 2009 that "in comparison with inorganic arsenic, much less is known regarding the toxicity and biotransformation pathways associated with dietary intake of DMA" and "although generally considered to be less toxic than inorganic arsenic, more information about the long-term exposure effects of
DMA may be necessary to evaluate fully the risk of rice consumption, given the high DMA content that has been reported in rice." Clearly, any further studies of this topic will need the support of reliable arsenic speciation analysis.

Meharg and Raab have argued that when it comes to testing rice, total arsenic could be used as a surrogate for inorganic arsenic [39]. This is based on their summary of the "numerous studies" in the literature that show that the inorganic arsenic content can be "extrapolated from total arsenic measurements." This may be an overly optimistic position, as the most recent results for rice on the supermarket shelves in the US had inorganic to total arsenic concentration ratios ranging from 11 to $80 \%$ [33]. The Joint Food and Agriculture Organization of the United Nations and the World Health Organization Expert Committee on Food Additives wrote in the summary of their Seventy-second meeting held in Rome, in February 2010 [34] that the proportion of inorganic arsenic in some foods varies widely and they considered that dietary exposure should be based on actual data rather than using generalized conversion factors for total measurements. The committee also thought that more accurate information on the inorganic arsenic content of food is needed to improve assessments of dietary exposures, and that there were problems associated with the analytical methodology needed to achieving this goal including "the lack of validated methods for selective determination of inorganic species in food matrices and the lack of certified reference materials for inorganic arsenic in foods." The comments echo those already made by the EFSA [29].

It seems then as though there is a strong case to be made for the availability of chemical measurement technology that is capable of providing reliable information about not just the total concentration of arsenic but also of the arsenic speciation, particularly the inorganic forms in a variety of foodstuffs and in rice in particular. However, results of the modeling of Xue et al., [31] discussed above in relation to consumption patterns in the US, make a case for the speciation of arsenic in vegetables, fruits, and fruit juices as well.

\section{Speciation Analysis}

As has become apparent for studies of the biogeochemistry of many of the elements, especially those that enter the human food chain, the information about chemical composition needed is not just the concentration of the total element, but about the concentrations of all the different compounds that contain the element of interest. This distribution of an element among various different chemical forms is known as "speciation" and the measurement of one, some, or all these various compounds is known as "speciation analysis." The International Union of Pure and Applied Chemistry has provided a definition [40] of chemical species as "specific forms of an element that are defined as to isotopic composition, electronic, or oxidation state, and/or complex or molecular structure." Speciation analysis is not to be confused with operationally defined speciation, which should really be called "fractionation." So that, for example, the measurement of the arsenic extracted from a soil sample by shaking in a dilute solution of EDTA does not give a number 
that corresponds to a specific chemical species, rather it establishes a fraction of the arsenic in that sample that is extractable by this reagent (and which might be related to the fraction that is available to plants via complexation with the ligands in root exudate). Sometimes it is not clear whether an analytical method is speciation or fractionation. For example, most relevant analytical texts describe a method for the determination of "phosphate" (meaning, probably, $\mathrm{PO}_{4}{ }^{3-}$ and associated protonated species) in which the absorbance is measured of the blue compound that forms on adding a reducing agent to an acidified solution of the sample to which ammonium molybdate has been added. Quantification is achieved by comparison with the absorbance of standard solutions that have been taken through the same procedure, though not necessarily at the time of analysis. However, despite the generally accepted title of such a method of "The Determination of Phosphate," all that is measured are those chemical entities in solution that give a blue product under the specified reaction conditions. Extensive investigation of the "molybdenum blue" chemistry has established conditions (acidity, reagent concentration, nature of the reducing agent, and time elapsed before measurement) that make the reaction more or less specific for $\mathrm{PO}_{4}{ }^{3-}$, depending on what else might be in the sample. It is also well known that many oxoanions, including arsenate, are potential interferents in this method.

Speciation analysis requires, therefore, methodology that is highly specific and this means that the methods usually include some high performance separation coupled with a highly specific instrumental technique. To date, we do not have chemical measurement methods that are guaranteed to provide unambiguous information about target species; the need to achieve such performance is one of the major factors that drives research and development in chemical measurement technology.

3.1. The Status of Arsenic Speciation. In the Web of Science database there are almost one thousand articles in which some form of the search terms "arsen" " and "speci" occur in the title. A quick visual examination shows that they are almost all concerned with speciation analysis. As not all the titles of these articles include the word "determination" or "analysis," it is likely that these 1000 articles are mostly in addition to the 4,000 articles identified above at the beginning of this article. The chronology of the 1,000 speciation articles is also shown in Figure 1. From which it can be seen that since the early nineties, the rate of publication has been increasing almost linearly (at 3.7 articles per year) such that in each of the last five years some 70 articles have appeared. Not all of these articles are concerned with some aspect of analytical method development; some are "applications" papers. None-the-less, there is clearly very significant activity in terms of analytical method development.

There are a variety of reasons for such continued activity: one is that none of the methods developed is satisfactory (for whatever reason) and publication activity reflects the activity of the community to "get it right." A contributing factor to this growing number of articles is undoubtedly the greater availability of instrumentation with improved intrinsic performance. For those situations where improved detection limits (for example) are the driving force, the next generation of, say, plasma source mass spectrometer provides improved performance when incorporated into the overall method as the element-specific detector. It is probably the case that since the early nineties we have seen four generations of these instruments. It is quite possible that the price of each successive generation has been less than that of the previous generation, thereby enhancing the cost effectiveness of the developments.

Another factor that often contributes to continued method development is the complexity of the ever-expanding range of samples about which information is required. Thus, each new combination of analyte(s) and matrix presents a new challenge and once a method has been developed, it is worthy of publication. Then there are many laboratories that cannot afford to invest in the latest instrumentation or are located in places where the infrastructure (such as stable power supplies or copious volumes of high purity argon) cannot support the operation of such instrumentation, and so there is an incentive to find ways in which the measurements can be made with more robust and/or less expensive instruments.

Finally, there are the practical aspects of time and money. Even those laboratories with all the latest equipment want to operate in the most cost-effective manner and that means high throughput and low operating costs, yet another set of incentives for continued method development.

3.2. Reviews of Arsenic Speciation Analysis. Not surprisingly, with a literature of nearly 1000 original articles, there is an associated secondary literature of review articles. There are 21 publications with the search terms "arsen" "and "speci*" and "review" in the title, 13 of which are concerned with the analytical methodology. Review articles are something of a mixed bag in terms of usefulness. Many that emanate from academic institutions are comprehensive compilations of the relevant articles put together by a graduate student as the introduction to a doctoral dissertation or by a postdoctoral worker "getting up to speed" with a new area. Often, such an article contains tables that summarize the contents of each article, but the text is little more than sentences made up of the titles of the articles together with some information taken from the abstract. While these articles certainly save the interested reader the considerable time of a complicated literature searching process, often the writers do not provide any critical commentary, which after all is what a review article in a primary peer-reviewed journal should provide for its readers. A couple of exceptions are worthy of note: any review article that features Kevin Francesconi as an author will deliver critical commentary (see for, example, [41]), and the Atomic Spectrometry Updates that appear on a regular basis in the Journal of Analytical Atomic Spectrometry are selective, critical, and are all written by teams of experts with many years of experience working in the relevant fields.

Of course, arsenic speciation features in review articles with a broader focus than just on the measurement of arsenic compounds; some reviews deal with methodologies for several elements or are concerned with particular sample types. For example, Gonzalvez et al. reviewed "nonchromatographic 
methods for speciation analysis" in 2009 [42]. They identified at least eight different strategies and included 11 elements in their survey. The article features several summary tables, the largest of which relates to arsenic speciation and contains information from 97 articles. The writers use the Web of Science database to identify the growth in the literature, which at the time the manuscript was submitted (November 2008) had reached a cumulative total of about 440 articles, 185 of which were concerned with some aspect of arsenic speciation (followed by selenium, with 75 articles, and then antimony, chromium and mercury tied for third place with 40 articles each). It should be remembered that this is a survey of the nonchromatographic methodology and does not necessarily reflect the relative efforts devoted to speciation analytical method development across the entire spectrum of analytical methodology. It is obvious from even a cursory glance at the tables for these elements that hydride generation plays a very important role. In the case of arsenic, 82 of the articles selected for inclusion in the table describe work in which hydride generation was a feature of the method. It is also obvious that all methods involve an optical atomic spectrometry detector of some sort, whereas none of the procedures has ICP-MS as the detector. Presumably, if a laboratory has the resources to operate an ICP-MS instrument, the separation of choice is chromatography.

The determination of arsenic species in environmental samples has been reviewed recently from a number of angles. Anawar restricted his scope to hydride generation with atomic absorption spectrometry [43]. Disappointingly for a review dated 2012, the author seems unaware of the extensive studies of the mechanism of hydride generation by reaction with borohydride over the past 10 years that have led, to use the words of experts [44], to "the definitive rejection of the "nascent hydrogen" hypothesis and the adoption of a reaction model based on direct transfer of hydrogen from boron to the element through the formation of analyteborane complex intermediates." The review also adopts a rather idiosyncratic classification of chromatographic separations and is not recommended reading. On the other hand, a review of speciation analysis featuring liquid or gas chromatography with ICP-MS detection [45] reveals that as far as environmental applications are concerned there are no methods for arsenic speciation featuring gas chromatography. The status of HLPC-ICP-MS is accurately summarized, although the issue of compound-dependent responses is not discussed even though at least one article that illustrates these quite dramatically [46] is included. The application of HPLC-ICP-MS to the determination of arsenic species in waters has been reviewed by Komorowicz and Barałkiewicz [47]. The article contains a table with 45 entries each of which summarizes an analytical procedure and as there are only so many different types of water, many of them describe essentially the same analysis. There is also a table that summarizes some analytical performance parameters, such as detection limit, with about 20 entries for each of the four major arsenic species and a smaller number for arsenobetaine, arsenocholine and trimethylarsine oxide. Values typically range between 1 and $0.01 \mu \mathrm{g} \mathrm{L}^{-1}$. Although there is a section on calibration equations, no slope values are given, and it would appear as though the whole issue of compound-dependent responses has not been addressed. This is a real shame, as the reviewers must have read closely many tens of relevant research articles. In a 2012 review [48], Radke et al. focus on voltammetry, hydride generation and chromatography. We learn that there are some applications featuring separation by gas chromatography, but these are confined to the determination of chemical warfare agents and their degradation products. As an aside, this seemingly rather esoteric area of analytical chemistry is the subject of a recent book [49]. Radke et al. are also not aware that arsine is not formed by the reaction of arsenite and hydrogen, and they give undue prominence to cathodic stripping voltammetry, but redeem themselves by including a solid discussion of the validation of analytical methods that contains a useful table of definitions of the more important parameters and some fairly critical commentary (i.e., probably justified): "currently, the application of some analytical procedures to routine environmental research without any control is very poor practice."

The status of elemental speciation in general up to about the year 2004 was comprehensively covered in a two textbooks edited by Cornelis et al. [50, 51]. The earlier volume was devoted to techniques and methodology, whereas the later volume dealt with applications in the environment, food, medicine, and occupational health. Acknowledged experts wrote most of the chapters.

\section{How Well Can We Measure Relevant Arsenic Compounds?}

In principle, there should be no problems with detection capability. Plasma source mass spectrometry instruments can detect concentrations as low as $0.0006 \mu \mathrm{g} \mathrm{L}^{-1}$ in a solution that is continuously introduced at about $1 \mathrm{~mL} \mathrm{~min}^{-1}$ with standard sample introduction via a nebulizer and spray chamber [52]. Even allowing for an instrument that is no longer brand new and a sample pretreatment that incorporates a 100-times dilution, it should still be possible to detect arsenic at around single digit $\mu \mathrm{g} \mathrm{kg}^{-1}$ in a solid sample. Obviously, if the total content is divided between several species, the detection capability of the individual species will be correspondingly poorer. Most of the rice we eat in the US contains at least double-digit $\mu \mathrm{g} \mathrm{kg}^{-1}$ concentrations of inorganic arsenic, which is anything between about 10 and $80 \%$ of the total arsenic. The detection capability of electrothermal atomization atomic absorption spectrometry (ETAAS) for arsenic is about two orders of magnitude poorer than that of ICP-MS, but even so, ETAAS is capable of measuring the total arsenic in rice with perfectly adequate precision. However, the technique is much less suitable for speciation analysis as the instrument cannot deal with a continuously flowing sample stream and so cannot function as a detector for chromatography or capillary electrophoresis. The detection capability of inductively coupled plasma optical emission spectrometry (ICP-OES) is more than an order of magnitude worse that that of ET-AAS, and this technique, 
although capable of accepting a chromatographic eluent, does not have the capability to function as a detector for the measurement of arsenic species in rice or any other foodstuffs, with the possible exception of seafood, which may contain well over $1000 \mu \mathrm{g} \mathrm{kg}^{-1}$ of total arsenic. All of the commonly encountered arsenic compounds in rice (arsenite, arsenate, dimethylarsinate and monomethylarsonate) will react the borohydride in aqueous solution to form the corresponding volatile hydride (both arsenite and arsenate form the same compound, $\mathrm{AsH}_{3}$ ). The extent of the reaction depends on the conditions, but without too much difficulty, almost all of the inorganic arsenic in a solution can be converted to arsine and transferred to the vapor phase. The introduction of this vapor into an atomic spectrometer increases the atom number considerably, so that the sensitivity may be increased as much as two orders of magnitude compared with conventional solution introduction. As the noise is not adversely affected, the greatly increased signal-to-noise ratio makes the limit of detection for arsenic by HG-AAS with a quartz tube atomizer similar to that of ETAAS (about $0.05 \mu \mathrm{g} \mathrm{L}^{-1}$ ). The range of instruments available for atomic fluorescence spectrometry (AFS) is much more limited than for AAS, OES, or atomic MS, but the integration of continuous flow HG with a hydrogen diffusion flame atomizer and hollow cathode lamp light source is the basis of instrumentation that can detect arsenic (and other hydride-forming elements and mercury) at sub $\mu \mathrm{gL}^{-1}$ values. The instrumentation can be interfaced with continuous flow separations and thus HPLC-AFS (with HG as the interface) is a viable technique for speciation analysis, and represents something of a niche market as a less expensive alternative to ICP-MS. Not surprisingly, the application of AFS to the speciation analysis of arsenic (and antimony, selenium, and mercury) has recently been reviewed [53].

Although electrochemical techniques, notably anodic stripping voltammetry (ASV), have the detection capability to measure inorganic arsenic species at sub $\mu \mathrm{gL}^{-1}$ values, these techniques are not really viable for speciation analysis. It is not possible to interface ASV with a continuous separation procedure such as HPLC and the technique only really responds to one species (arsenite), so any speciation scheme involving ASV requires sequential conversion of the analyte species to a common precursor after they have been separated. Electrode surfaces need to be regenerated frequently and this is time consuming and may require considerable operator skill and experience. Calibration by the method of standard additions is often needed. Having said that, there may be a niche application area for ASV and that is the analysis of waters for the inorganic arsenic content. Seawater contains enough dissolved salts that it may not be necessary to add any additional background electrolyte, and so samples can be analyzed with the absolute minimum of pretreatment. Voltammetric techniques were featured in the recent review by Radke et al. [48] described above, in a 2009 review by Mays and Hussam [54], and in a 2007 review by Luong et al. [55], and were also included in a 2004 review of methods for the determination of inorganic arsenic in water by scientists in one of the world's leading ASV laboratories, that of Professor Richard Compton in Oxford,
UK [56]. This review although highly cited (111 times at the time of writing) is now a bit dated. It does not, for example, mention the combination of HG with ETAAS or the use of reaction/collision cell technology in ICP-MS.

As all articles that are published in the peer-reviewed literature have been scrutinized by several experts and probably revised prior to publication, it is unlikely that such an article will describe the development and application, by one competent research laboratory, of a method for the determination of arsenic species that is seriously flawed and inaccurate. There is, though, a tendency for titles of articles to be slightly misleading: it is not uncommon to find under the heading of, say, "determination of arsenic species in natural waters," a description of a method that did not have the detection capability to measure the target analytes at the concentrations in the real sample, but was capable of accurate measurement of analytes spiked into the sample matrix. So when we take the research literature one article at a time, it is not necessarily obvious that there might still be problems with the methodology. However, if we compile results from several articles, then a slightly different picture emerges. For example, many laboratories have chosen to analyze the National Institute of Standards and Technology (NIST) certified reference rice flour (SRM 1568a) for the arsenic species as part of the validation of a method for the determination of arsenite, arsenate, MMA, and DMA in rice. The material is only certified for the total arsenic content $\left(290 \pm 30 \mu \mathrm{g} \mathrm{kg}^{-1}\right)$ and not for the arsenic species, but it seems reasonable that under appropriate storage conditions, the arsenic species would not interconvert and/or be lost. According to the certificate for this material the supplier describes it as " $100 \%$ long grain from Arkansas." The material is described as "unpolished" by Narukawa et al. [57] in an article that explains that white rice is made by "polishing" brown rice, a process in which "the outer bran layers are milled off." They present results to show that as the bran layers are removed, the total arsenic content decreases significantly.

4.1. The Arsenic Speciation in NIST SRM 1568a. In a 2011 article, Batista et al. report [82] their own results for the analysis of this material and tabulated the results of 11 previously reported analyses. It is perhaps worth noting, in passing, that they chose to describe the results of their investigation into the arsenic content of Brazilian rice in the Journal of Hazardous Materials. Since then, another 7 set of values have been reported in 2011 (three of them are in one paper), and, so far in 2012, another 4 articles have made it through the peer review process and into print, two of which contain two sets of values. As it happens, Batista et al. were somewhat selective in their choice of entries for their table and the literature prior to 2011 actually contains 25 results of at least partial speciation analyses of this material. The grand total would appear to be 39 distinct data sets for the speciation analysis of NIST SRM 1568a, a summary of which is given in Table 1, but this is not guaranteed to be all of the data sets reported. There is some doubt as to whether the entry for [68] (2007) is really a separate set of data as the numbers are identical to those given in the two 2005 articles $[64,65]$ from the same research group, which have 
TABLE 1: Results for the arsenic speciation in NIST SRM 1568a (rice flour) in $\mu \mathrm{g} \mathrm{kg}^{-1}$. The material is not certified for species, only the total $\left(290 \pm 30 \mu \mathrm{g} \mathrm{kg}^{-1}\right.$, where the \pm term is an expanded uncertainty and corresponds approximately to a $95 \%$ confidence interval).

\begin{tabular}{|c|c|c|c|c|c|c|c|}
\hline Arsenite & Arsenate & DMA & MMA & Inorganic sum & Sum of species & Year of Publication & Reference \\
\hline & & $174 \pm 9$ & $8 \pm 2$ & $92 \pm 4$ & 274 & 2001 & {$[58]$} \\
\hline & & 239 & 0 & 85 & 324 & 2001 & {$[58]$} \\
\hline 75 & 12 & 180 & 9 & 97 & 276 & 2003 & {$[59]$} \\
\hline $67 \pm 4$ & $39 \pm 3$ & $158 \pm 5$ & $13 \pm 2$ & 108 & 277 & 2003 & {$[60]$} \\
\hline \multirow[t]{2}{*}{$55 \pm 1$} & $54 \pm 3$ & $165 \pm 8$ & $15 \pm 2$ & 109 & 288 & 2004 & {$[61]$} \\
\hline & & 171 & & 70 & 241 & 2004 & {$[62]$} \\
\hline $80 \pm 14$ & 0 & $160 \pm 24$ & 2 & $80 \pm 14$ & 242 & 2005 & {$[63]$} \\
\hline $68 \pm 4$ & $20 \pm 2$ & $135 \pm 4$ & $8 \pm 1$ & 88 & 231 & 2005 & {$[64,65]$} \\
\hline \multirow[t]{2}{*}{ $\pm 2 \mathrm{~s}$} & & $168 \pm 9$ & $12.0 \pm 0.2$ & $87 \pm 9$ & 267 & 2005 & [66] \\
\hline & & $148 \pm 7$ & $11.0 \pm 0.5$ & $101 \pm 7$ & 260 & 2005 & {$[66]$} \\
\hline 0 & 58 & 116 & 10 & 58 & 184 & 2006 & {$[67]$} \\
\hline $68 \pm 4$ & $20 \pm 2$ & $135 \pm 4$ & $8 \pm 1$ & 88 & 231 & 2007 & {$[68]$} \\
\hline $60 \pm 10$ & $28 \pm 16$ & $148 \pm 22$ & $12 \pm 3$ & 88 & 248 & 2007 & [69] \\
\hline $69 \pm 1$ & $33 \pm 1$ & $155 \pm 2$ & $9.2 \pm 0.2$ & 102 & 266 & 2007 & {$[70]$} \\
\hline $52 \pm 1$ & $44 \pm 2$ & $173 \pm 2$ & $12 \pm 0.8$ & 96 & 281 & 2008 & {$[71]$} \\
\hline \multirow[t]{2}{*}{$67 \pm 5$} & $36 \pm 1$ & $162 \pm 1$ & $5 \pm 1$ & 103 & 271 & 2008 & {$[72]$} \\
\hline & & & & $82 \pm 9$ & 268 & 2008 & {$[73]$} \\
\hline \multirow[t]{4}{*}{$55 \pm 6$} & $41 \pm 3$ & $166 \pm 6$ & $10 \pm 2$ & 96 & 272 & 2009 & {$[74]$} \\
\hline & & $180 \pm 3$ & sum of org & $110 \pm 10$ & 290 & 2009 & {$[75]$} \\
\hline & & $185 \pm 3$ & sum of org & $99 \pm 2$ & 284 & 2009 & {$[76]$} \\
\hline & & $175 \pm 5$ & 0 & $87 \pm 7$ & 262 & 2009 & {$[77]$} \\
\hline $52 \pm 3$ & $20 \pm 3$ & $128 \pm 6$ & $10.4 \pm 0.2$ & 72 & 210 & 2009 & {$[78]$} \\
\hline $53 \pm 1$ & $45 \pm 1$ & $175 \pm 2$ & $13 \pm 2$ & 98 & 231 & 2010 & {$[68]$} \\
\hline $71 \pm 6$ & $36 \pm 4$ & $188 \pm 4$ & $14 \pm 2$ & 107 & 309 & 2010 & [79] \\
\hline 78 & 32 & 148 & 12 & 110 & 270 & 2010 & {$[80]$} \\
\hline $69 \pm 1$ & $22 \pm 1$ & $171 \pm 8$ & $9 \pm 2$ & $91 \pm 6$ & 271 & 2010 & {$[81]$} \\
\hline $63 \pm 4$ & $50 \pm 3$ & $142 \pm 4$ & $15 \pm 4$ & 113 & 273 & 2011 & {$[82]$} \\
\hline \multirow[t]{4}{*}{$74.40 \pm 0.09$} & $35.1 \pm 0.9$ & $158 \pm 2$ & $10.50 \pm 0.01$ & 109.5 & 278 & 2011 & {$[83]$} \\
\hline & & $131 \pm 6$ & $72 \pm 4$ & $86 \pm 6$ & 289 & 2011 & {$[84]$} \\
\hline & & $134 \pm 7$ & $14 \pm 5$ & $101 \pm 3$ & 249 & 2011 & {$[84]$} \\
\hline & & 129 & 16 & 98 & 243 & 2011 & {$[84]$} \\
\hline \multirow[t]{4}{*}{51.9} & 39.6 & 188 & 12 & 91.2 & 291 & 2011 & {$[85]$} \\
\hline & & $160 \pm 20$ & 0 & $110 \pm 5$ & 270 & 2011 & {$[86]$} \\
\hline & & $168 \pm 7$ & sum of org & $76 \pm 9$ & 244 & 2011 & [87] \\
\hline & & $200 \pm 12$ & $11 \pm 1$ & $79 \pm 7$ & 290 & 2012 & {$[88]$} \\
\hline 0 & $96 \pm 1$ & $166 \pm 2$ & $12 \pm 1$ & 96 & 274 & 2012 & {$[88]$} \\
\hline 0 & $104 \pm 4$ & $168 \pm 2$ & $14 \pm 2$ & $104 \pm 4$ & 286 & 2012 & [89] \\
\hline 0 & $105 \pm 2$ & $180 \pm 5$ & $13.2 \pm 0.2$ & $105 \pm 2$ & 298 & 2012 & [89] \\
\hline $53 \pm 1$ & $46.1 \pm 0.7$ & $172 \pm 2$ & $13.2 \pm 0.3$ & 99 & 285 & 2012 & {$[90]$} \\
\hline $74 \pm 7$ & $30 \pm 3$ & $165 \pm 7$ & $15.0 \pm 0.7$ & 104 & 284 & 2012 & [91] \\
\hline
\end{tabular}

Notes. The \pm terms are as provided by the researchers. They are predominantly standard deviations for some small number of replicates. Further details are provided in the text. Values have been rounded to the first uncertain digit. The numbers in the "sum" columns may differ from the sums of the numbers presented in the individual columns because of rounding effects. Not all researchers reported values for all four species. No \pm terms have been calculated for the sums where this had not been done by the researchers, though clearly this would be possible for many entries. Many of the sample extraction methods did not preserve the redox state of the inorganic arsenic species. 
only been entered once. When the data presented by Batista et al. (i.e., the 12 entries in the table in their 2011 article) are examined, the situation does not look very reassuring: values for arsenite range (in $\mu \mathrm{g} \mathrm{kg}^{-1}$ ) from 52 to 129, for example. However, it turns out that one of the entries in the table is wrong; the results for another material (not SRM 1568a) had been copied from the original paper [64]. It further turns out that the values for the inorganic species may not all be correct, as they are the results of procedures that, as the original researchers acknowledge, cause redox changes in the inorganic species. So rather than trying to draw conclusions from the information presented by Batista et al., the picture given by Table 1 is a more accurate representation of what the international analytical chemistry community is capable of in terms of the speciation analysis of NIST SRM 1568a. Where possible, information about the uncertainty reported by the researchers has been included. For many of the entries, the \pm term is the standard deviation of a small number of replicate analyses. This is assumed to be an entirely separate analyses, not $n$ replicate measurements of the final solution, though this is not always explicitly stated. In one case [69], the \pm term is simply half the range quoted by the researchers, and is significantly larger in this case as the method was a rapid screening thin-layer chromatographic separation followed by laser-ablation ICP-MS. In another case [66], the \pm term is two standard deviations, and in yet another case [84] the \pm term was calculated from a number that the researchers called " $\mathrm{CV}(\mathrm{r})$ " that was expressed as a percentage as though it was the percent relative standard deviation, but which was not defined in the article. These researchers presented three different sets of results for the CRM, all of which are included in Table 1; they also presented the results of 14 previously published values for the speciation of this material. This presentation also contains some errors, though none as serious as that of Batista et al. Curiously, after many pages of rigorous statistical evaluation of their results according to internationally agreed metrology protocols $[93,94]$, they describe the results of their analysis of SRM 1568a simply as "generally in good agreement" with the previous results. At least two others of the publications contain partial listings of the previously published values. It is considered advisable to check any such list that might appear in a future publication against the numbers in the original article, especially if some important conclusion is to be drawn. Since late 2009, a rice reference material certified for the arsenic species has been available from the National Metrology Institute of Japan, and it is possible that a similar list of results for this material will be appearing in the analytical literature.

On the other hand, what can be said about the arsenic species content of SRM 1568a? Almost all researchers report results for 4 or fewer species, and there would seem to be agreement that the material only contains inorganic arsenic and the two methylated species, as these are what are detectable by the methods employed. Obviously, these species are what appear in the solution as the result of the various extraction methods and do not necessarily indicate what chemical forms are present in the solid rice grain. However, in the context of human consumption the cooking and digestion processes are such that whatever the precursor compounds were, it is the compounds measured by most speciation analysis methods that are available for adsorption from the stomach and gut. Almost always the "sum of species" arsenic is less than the certified total $\left(290 \pm 30 \mu \mathrm{g} \mathrm{kg}^{-1}\right)$, though most researchers do not attempt any statistical evaluation of the difference. Many researchers estimate the detection limit of their method, obtaining values that were species dependent and were typically single digit $\mu \mathrm{g} \mathrm{kg}^{-1}$ in the dried material. So it is possible that the material does contain several other arsenic compounds all present at say $5 \mu \mathrm{g} \mathrm{kg}^{-1}$. This is irrelevant with regard to the ability of laboratories to detect potentially harmful compounds, as it is well known that the inorganic and methylated forms are, respectively, very much more and more toxic than any other arsenic compounds found in the natural environment.

Many of the methods reported cause redox changes in the inorganic species and so there is greater uncertainly over the concentrations of arsenite and arsenate than over the total inorganic arsenic concentration, which would appear to be $95 \pm 4 \mu \mathrm{g} \mathrm{kg}^{-1}$ (95\% CI $n=39$ ). The standard deviation is $13 \mu \mathrm{g} \mathrm{kg}^{-1}$, so in the data set of 39 there are no results outside the \pm 3 standard deviations (and which might, therefore, be considered outliers).

The material contains a much higher concentration of DMA than of MMA and the values for DMA are more variable than those for inorganic arsenic, with a mean of $163 \pm 7 \mu \mathrm{g} \mathrm{kg}^{-1}(95 \% \mathrm{CI} n=34)$ and a standard deviation of $23 \mu \mathrm{g} \mathrm{kg}^{-1}$. The data set includes 2 results outside \pm 2 standard deviations, 1 of which is outside \pm 3 standard deviations. If this value $\left(239 \mu \mathrm{g} \mathrm{kg}^{-1}\right)$ is excluded, the mean value drops to 161 , the standard deviation to 20 and the $95 \%$ confidence interval to $6 \mu \mathrm{g} \mathrm{kg}^{-1}$.

Plotting the results chronologically does not lead to any further insights. There has been no obvious change in the values reported as a function of time, the latest values also cover just wide a spread as the earlier results: the 14 results for inorganic arsenic reported in 2011 and 2012 cover a range of 76 to $110 \mu \mathrm{g} \mathrm{kg}^{-1}$; the 10 results reported from 2001 to 2005 cover the range 70 to $109 \mu \mathrm{g} \mathrm{kg}^{-1}$.

Unfortunately, just as we might be able to say something about (a) the arsenic speciation of this NIST SRM 1568a material, and (b) the ability of the analytical community to measure this speciation, it is no longer available: the NIST website indicates that at the time of writing (November 2012) the material is "out of stock." A recent development is described below in Section 6, Concluding Remarks.

4.2. The Arsenic-in-Rice Proficiency Test (IMEP-107). However, before attempting any further analysis of the data in Table 1, it is instructive to examine the results of a real proficiency test of laboratories' abilities to measure (a) total arsenic in rice and (b) the inorganic arsenic content of rice. In March of 2010, the European Commission's Joint Research Centre (JRC) Institute for Reference Materials and Measurement (IRMM) published a report entitled "Report of the seventh interlaboratory comparison organized by the European Union reference laboratory for heavy metals in 
feed and food IMEP-107: total and inorganic As in rice" [95]. A summary of the results later appeared in issue 4 of the 2011 Trends in Analytical Chemistry [96]. IMEP stands for the International Measurement Evaluation Programme. According to the JRC website, the main objective of this exercise was to evaluate the capabilities of nominated national reference laboratories and control laboratories in the area of food and feed in the determination of total and inorganic arsenic. The website also describes the exercise as a "proficiency test" even though these words are not used in the title of the report. In fact, the exercise was not confined to "nominated national reference laboratories," but was open to any laboratory that wished to participate. In the end, 103 laboratories from 35 countries registered; results were obtained from 98 laboratories for total arsenic and from 32 laboratories for inorganic arsenic. Participants were sent a bottle containing about $20 \mathrm{~g}$ of rice flour and requested to perform two or three independent analyses using the method of their choice. However, some additional instructions were issued. Results were to be reported on a dry weight basis and detailed instructions were provided as to how to dry the material (heat $1 \mathrm{~g}$ for $18 \mathrm{~h}$ at $85 \pm 2^{\circ} \mathrm{C}$; cool in a desiccator for $30 \mathrm{~min}$ and reweigh) and participants were told very clearly not to use the dried material for analysis, though they were not told why. The most likely reason is that the some arsenic compounds can be lost during the drying process (though it has proved difficult to find direct evidence of this in the primary literature). Participants were also told to correct their results for recovery, though were not given any instructions on how to do this. As it turned, out most of the laboratories reporting results (for total and for inorganic arsenic) did not correct for recovery, whereas, almost all the laboratories did correct for moisture content, which varied from 0.5 to $14 \%$. Participants were asked to report the individual results, the mean and its associated uncertainty in the same manner as would be presented to a customer.

The sample material was prepared from $10 \mathrm{~kg}$ of rice purchased in Aberdeen, Scotland. No information is provided as to the nature of the material, so it is not known if this was "white" or "brown" rice, or where it was harvested. At IRMM, the material was cryogenically ground to a particle size of less than $250 \mu \mathrm{m}$, homogenized in a three-dimensional mixer and, without any further sterilization, packaged in 60-mL bottles (material not specified) fitted with a PE (not defined) insert and screw cap. Of the 228 bottles produced, 31 were randomly selected for homogeneity and short-term stability tests. An unspecified number of bottles were sent to each of seven expert laboratories, who were asked to analyze the material by methods of their choice and to provide a clear and detailed description of how the uncertainty was calculated. The mean of the expert laboratory means was taken as the "assigned" value (also called the "reference value" in the reports) and the associated "standard uncertainty" was calculated as the square root of the sum of the squares of the "standard uncertainties" of the (a) characterization by the expert laboratories, plus (b) contribution for the betweenbottle homogeneity, and plus (c) contribution derived from the stability study. All of this is in accordance with the International Standards Organization guide 35 [97]. The organizers reported that the material was both homogeneous and stable according to the appropriate criteria.

Applying all of these formulae produced a value of $172 \mu \mathrm{g} \mathrm{kg}^{-1}$ for the assigned value of the total arsenic with an associated uncertainty of $\pm 9 \mu \mathrm{g} \mathrm{kg}^{-1}$, and of $107 \mu \mathrm{g} \mathrm{kg}^{-1}$ for the inorganic arsenic with an associated uncertainty of $\pm 7 \mu \mathrm{g} \mathrm{kg}^{-1}$. The organizers then calculated a quality parameter for each laboratory called the zeta $(\zeta)$ score defined as

$$
\zeta=\frac{x_{\mathrm{lab}}-X_{\mathrm{ref}}}{\sqrt{u_{\mathrm{ref}}^{2}+u_{\mathrm{lab}}^{2}}},
$$

where $x_{\text {lab }}$ is the mean value obtained by the lab, $X_{\text {ref }}$ is the assigned value, $u_{\text {ref }}$ is the standard uncertainty of the reference value, and $u_{\text {lab }}$ is the standard uncertainty reported by a participant. Participant's results were classified on the basis of the value of the modulus of the zeta-score as "satisfactory" $(\leq 2)$, "questionable" $(>2, \leq 3)$, or "unsatisfactory" $(>3)$. For total arsenic, 98 laboratories s submitted results (one of whom submitted two sets by different methods); only one of the expert laboratories participated and submitted a result by a method different from the one used in the exercise to establish the assigned value. Of the 92 results that were amenable to the calculation of an zeta-score, 54 were satisfactory, 15 were questionable and 23 were unsatisfactory. Taking the possibly hard-nosed position that the 11 results that could not be included in this calculation were also unsatisfactory, one concludes that only just over half (55\%) of the participating laboratories obtained results that were satisfactory.

With regard to the measurement of the inorganic arsenic species, only 33 laboratories submitted results, 28 of which were amenable to the calculation of a zeta-score. The results were: satisfactory 16 , questionable 2 , and unsatisfactory 10 . Overall the outcome was much the same as for total arsenic: about half the participants (48\%) obtained a satisfactory result.

There is considerably more material in both the summary article [96] and the original report [95], including in-depth accounts of the problems associated with (a) the reporting of uncertainties, (b) the correction for moisture content and (c) the correction (or not) for recovery. These topics are really beyond the scope of the current review, whose purpose is to point out that even after working on the development of analytical methodology for arsenic speciation in rice for at over 10 years (see Table 1); only half of the participants from the international analytical community in a recent collaborative trial could get a result that the organizers would call satisfactory.

The trial organizers also collected information about the analytical methods used, some very limited details of which are provided in the tables in the full report. The methods used by the expert laboratories are described in more detail and it is possible to ascertain that four of the six expert laboratories that determined the inorganic arsenic species did so by extraction followed by HPLCICP-MS. The other methods were (a) separation of the organic and inorganic forms by liquid-liquid extraction, conversion to arsenite with quantification by flow injection HG-AAS, and (b) separation of the organic and inorganic 
forms by liquid-liquid extraction followed by quantification by high resolution ICP-MS (as the medium contained a high concentration of $\mathrm{HCl}$ ). The organizers write that, "the main conclusion that can be derived from this exercise is that the concentration of inorganic arsenic determined in rice does not depend on the analytical method applied," but not enough of the raw data is available to be able to independently check this conclusion. If anything, there is evidence that some laboratories obtained systematically low results as the kernel plot [98] for the inorganic arsenic results is clearly not symmetrical about the assigned value and shows a possible shoulder on the low concentration side.

One might have more confidence in this statement if the reports did not contain other statements with which one can argue. For example, one conclusion is that "no particular problem related to the determination of inorganic As in rice has been detected in this proficiency test and the performance of the participating laboratories was satisfactory." We are also told, "the expert laboratories found a better agreement on the concentration of inorganic As than on the total concentration on (sic) As for which a wider dispersion of results was observed." Although the latter part of this statement is true, it does support the conclusion drawn in the former part. The spread of results in a proficiency test such as this are described by the modified Horwitz function [99]. For concentrations below $120 \mu \mathrm{g} \mathrm{kg}^{-1}$, the reproducibility standard deviation is given by $0.22 c$, for concentrations above $120 \mu \mathrm{g} \mathrm{kg}^{-1}$ but below $13.8 \%$, the reproducibility standard deviation is given by $0.02 c^{0.8495}$, and for concentrations above $13.8 \%$, the reproducibility standard deviation is given by $0.01 c^{0.5}$, where $c$ is expressed as a dimensionless mass ratio (e.g., a concentration of $100 \mu \mathrm{g} \mathrm{kg}^{-1}$ is entered into the equations as $1.00 \times 10^{-7}$ ). Applying these equations to the assigned values of $172 \mu \mathrm{g} \mathrm{kg}^{-1}$ and $107 \mu \mathrm{g} \mathrm{kg}^{-1}$ for total and inorganic arsenic, respectively leads to estimates for the corresponding reproducibility standard deviations of 36 and $24 \mu \mathrm{g} \mathrm{kg}^{-1}$, respectively. That is, under normal circumstances, it would be expected that in a proficiency test with these assigned values, the ratio of the reproducibility standard deviations would be 1.5. In fact, the values calculated from the results submitted by the expert laboratories had a ratio of $17 / 9=1.9$. The ratios may be compared on the basis of an F-test, which shows that the difference is not significant and thus the relative spreads of the two sets of data are within the bounds of what would be expected for this kind of proficiency test.

There are some other interesting features of the results (which are not discussed by the organizers). For example, in the light of the suggestion that the determination of total arsenic could be used as a surrogate for the inorganic arsenic content of rice [39], it is instructive to examine the ratios of inorganic to total obtained by the 6 expert laboratories. The values may be readily calculated from the data provided and are $0.640,0.552,0.562,0.835,0.564$, and 0.632 . Application of the $Q$-test identifies 0.835 as an outlier (with $95 \%$ confidence), and so out of 6 expert laboratories, one cannot get a ratio of inorganic to total arsenic that has come from the same background population as the results of the other laboratories.
It can be concluded that there are still some problems with the ability of the analytical community to make reliable measurements of not only the total arsenic concentration in rice but also of the inorganic arsenic species concentration as well.

It is evident that similar problems are being encountered with the determination of inorganic arsenic in other foodstuffs. The JRC has organized further IMEPs around the measurement of inorganic arsenic. Results for two of theses studies (IMEP-30 and IMEP-109) have been reported in 2011 [100] in which the organizers of the trials write about the 22 results submitted, "with such a scattering of results it was not possible to derive any conclusion abut the concentration of iAs (sic) in this test material." This is hardly surprising when the outcome of the expert laboratories efforts to establish an assigned value was "strong discrepancies," and it was concluded that "it was not possible to establish an assigned value for this measurand" and therefore (of course), "the laboratories' results for iAs could not be scored." The outcome of IMEP-112 appeared in 2012 [101]. Three materials were involved, two of which were prepared in a manner similar to that of the rice used in IMEP-107 described above: wheat (ground grains - the word "flour" was not used) and algae (seaweed powder-Fucus vesiculosis-commonly known as bladderwrack). The third material (powdered vegetable food) was an NIST certified reference material (SRM 1570a spinach leaves, certified for total arsenic) repackaged so that participants would not necessarily recognize it. For this study, 74 laboratories registered from 31 countries and 65 reported results (though about the same number that reported inorganic arsenic values in the rice study also reported inorganic arsenic values). The assigned values for inorganic arsenic were: wheat $169 \mu \mathrm{g} \mathrm{kg}^{-1}$, vegetable food $54 \mu \mathrm{g} \mathrm{kg}^{-1}$, and algae $188 \mu \mathrm{g} \mathrm{kg}^{-1}$. Following the identical protocol to that described above for IMEP-107 (involving the zeta-scores), it transpired that for the wheat 21 out of 40 laboratories (53\%) got a "satisfactory" result; for the vegetable food, 16 laboratories out of 41 (39\%) got a satisfactory result; and for the algae, only 7 laboratories out of $40(18 \%)$ got a satisfactory result. Again, the two articles (and presumably the original reports) contain much in-depth discussion of the results. In the case of IMEP-112, the main conclusion is very hard to rationalize with the information disclosed in the article. As for IMEP107, we are told "the concentration of inorganic arsenic determined in any of the matrices covered does not depend on the analytical method applied." Later in the conclusion, we learn that "two existing standards (meaning standard methods) for the determination of iAs did provide biased results when applied to algae." Earlier in the article, we learn (a) that the results provided by one of the expert laboratories for wheat and algae were excluded because of problems arising from the addition of hydrogen peroxide, and (b) "this exercise provided evidence that the determination of iAs in... [wheat] may require some extra care in the extraction step." It transpires that hydrogen peroxide was again implicated, but this time it is necessary to add it and that "several of the laboratories that underestimated iAs in wheat did not add $\mathrm{H}_{2} \mathrm{O}_{2}$ during the digestion of the matrix." 


\section{Possible Sources of Problems with the Methodology}

Although the logical place to begin might be the sampling step as this is where the analytical method begins in practice, instrument-based issues will be considered first as these are (possibly) better understood that problems with other steps in the method.

\subsection{Instrumental Techniques}

5.1.1. Atomic Spectrometry. For all of the time period relevant to this review, the literature describing analytical methods featuring some facet of atomic spectrometry (optical and mass) has been reviewed on an annual basis in the Atomic Spectrometry Updates (ASU) published in the Journal of Analytical Spectrometry (JAAS). Both JAAS and ASU have recently celebrated their 25th birthdays, an occasion marked by a number of reflection pieces including one describing the birth, growth and development of the ASU [102]. The scope of the Updates has changed over the years reflecting developments in analytical atomic spectrometry instrumentation and application. In 2009, an ASU devoted to elemental speciation was created [103], the fourth of which has just appeared [104]. The three elements that feature most prominently in the section on individual elements are arsenic, mercury and selenium. The ASU writers are selective in what work is included in the Update, so the total of 246 references cited in the $2012 \mathrm{ASU}$ are not the total for the review period, which is approximately the 12-month period starting in January 2011. Of these 246 references, 40 were concerned with some aspect of arsenic speciation methodology.

Of course, the Atomic Spectrometry Updates focus on advances in atomic spectrometry so that methodology that features molecular mass spectrometry or electrochemistry is excluded. Having said that, it is probably true that most of the current methods being developed for arsenic speciation analysis do, in fact, involve some sort of atomic spectrometry detector. The reasons are not hard to discern, atomic spectrometry is, in principle, element-specific. The extent to which this specificity can be realized in practical instrumentation has been a major driving force for instrumental development over the years, such that the field can be considered sufficiently mature that we have a good understanding of the factors that can cause an atomic spectrometer to respond to some chemical entity other than the target analyte atoms (or ions, in the case of mass spectrometry). We also have a good understanding of the factors that cause the atom or ion number density in the atomizer produced from the sample to be different from that for the same concentration of element in a standard. As a result, we have developed a variety of strategies for detecting and overcoming these various interferences that would cause inaccuracies in the methodology. Another inherent characteristic of atomic spectrometry that makes it suitable choice for arsenic speciation analysis is that the instrumental detection limits (IDL) are low enough for methods that incorporate atomic spectrometry techniques to be useful (as was discussed above). A detailed critical evaluation of IDL is beyond the scope of the current review, but it is a topic that the community still does not handle very well, especially when the limit in question is to be calculated for a compound separated by chromatography. Thoughtful evaluation of detection limit issues can be found in the series of papers by Voigtman [105] Voigtman and Abraham [106].

Atomic spectrometers are subject to interferences that cause bias in the results. Interferences have their origin in the composition of the solution introduced to the spectrometer either because of components cause the atom (or ion) number density interrogated by the detector for a given concentration to be different from that interrogated for the same concentration of analyte in a standard, or because a component of the solution other than the target analyte produces a response. The interference can arise from components of the original sample matrix or from the reagents added in the various sample preparation stages. Understanding and overcoming these interference effects have been major driving forces in method and instrumental development for many years and are responsible, for example, for "background correction" technologies for atomic absorption spectrometry, and "collision-reaction cell" technologies in plasma source mass spectrometry. Developments in instrumentation can also be followed in an annual Atomic Spectrometry Update [107].

5.1.2. Particular Problems with ICP-MS. It should be well known by all laboratories operating ICP-MS instruments that the determination of arsenic is subject to some particular interferences. The presence of chlorine in the sample, most likely as the chloride ion, gives rise to the formation of ${ }^{40} \mathrm{Ar}^{35} \mathrm{Cl}^{+}$at $\mathrm{m} / \mathrm{z} 75$ and in many instruments with quadrupole mass analyzers this ion cannot be distinguished from ${ }^{75} \mathrm{As}^{+}$and so the signal is enhanced. The problem may be overcome by separating chloride from any arsenic containing species, as is often the case with HPLC separation, or by using an instrument that has the additional capability of performing some gas-phase chemistry inside the mass spectrometer. Most manufacturers of ICP-MS instruments offer the option of a collision/reaction cell in which unwanted molecular species, such as ${ }^{40} \mathrm{Ar}^{35} \mathrm{Cl}^{+}$, may be dissociated by collision with a bath gas, such as helium. Alternately, by introducing a gas, such as $\mathrm{O}_{2}$ or $\mathrm{CH}_{4}$ to react with ${ }^{75} \mathrm{As}^{+}$, detection can be shifted to $\mathrm{m} / \mathrm{z} 91$, in the case of ${ }^{75} \mathrm{As}^{16} \mathrm{O}^{+}$ [89], or $\mathrm{m} / \mathrm{z} 89$ in the case of ${ }^{75} \mathrm{As}^{12} \mathrm{CH}_{2}{ }^{+}$[83]. Yet a third option is to use a spectrometer with sufficient resolving power to be able to differentiate between the species at the nominal $\mathrm{m} / \mathrm{z}$ of 75 [92].

Perhaps less well known is the influence of carbon on the extent of the ionization of arsenic atoms in the plasma; it appears some recent analyses of fruit juices for the arsenic content whose results received considerable national media coverage in the US in 2011 may be inaccurate, as it has been suggested that the results are biased high because of the carbon enhancement effect [108]. The effect was first reported by Mermet's group in 1991 [109] and shown by Larsen and Sturup in 1994 [110] to be a benefit in the determination of arsenic (and selenium) species by HPLC-ICP-MS. The carbon was added as methanol (3\%) to the mobile phase. Since 
then, almost all such arsenic speciation methodologies have featured the addition of carbon to the plasma in this form, though recently Raber et al. added carbon dioxide to the plasma gases instead [88]. Compared with the signal obtained from an aqueous matrix, the presence of carbon can cause an enhancement of up to 6-7 fold. There is probably a limit to the percentage of methanol in a solution that is continuously introduced by conventional nebulization into an ICP source before the plasma is extinguished, but with a suitable desolvation system and decreased flow rate, percentages as high as 70 have been introduced. Baba et al. [111] devised an arsenic speciation procedure in which HPLC with a complicated 6step gradient program produced eluent (at $0.15 \mathrm{~mL} \mathrm{~min}^{-1}$ ) containing $70 \%$ methanol and a whiff of formic acid $(<0.1 \%)$ during one of the stages. They showed the effect of methanol in a separate, flow-injection experiment for 9 species in which $2 \mu \mathrm{L}$ of solutions containing $50 \mu \mathrm{g} \mathrm{L}^{-1}$ of arsenic and methanol concentrations from 0 to $70 \%$ were delivered to the instrument. Although the results are a little difficult to see (the figures are rather small), it appears that in $70 \%$ methanol the relative sensitivities for the four species of interest in rice were MMA 100\%, DMA 92\%, arsenate 78\%, and arsenite 28\%. It also appears that the signal for arsenite in $70 \%$ methanol was about 20 -times that in water.

Most modern sample preparation procedures do not completely convert all unwanted carbon-containing species to carbon dioxide, but will solubilize enough carbon-containing compounds to cause a measurable enhancement in the arsenic signal. Sample preparation issues are discussed below.

Even less well known, or at least acknowledged and discussed, is the phenomenon of compound-dependent responses. The existence of these goes against "conventional wisdom" in plasma spectrometry, which holds that the extent of atom/ion formation in the plasma is independent of the form of the element introduced. As Zavala et al. [112] put it, in an account of the determination of arsenic species in rice, "by using the ICP-MS as the detection system the calibration is species independent." And they went on to use the average of the arsenite/arsenate calibrations for the quantification of DMA, MMA and arsenobetaine.

However, in the report mentioned above [110], Larsen and Sturup, present results for the responses to a $1 \mu \mathrm{g} \mathrm{L}^{-1}$ solution of arsenic introduced to the ICP-MS instrument as 8 different species. The responses are shown in Table 2, from which it can be seen (a) that all of the compounds gave different responses, (b) the sensitivity for arsenite was highest and (c) the responses for the methylated compounds are significantly lower.

They did not discuss what might be considered the most obvious explanation, namely that the original compounds were not of identical purity. However, this should not be necessarily dismissed out of hand; my own research group has encountered problems with the not just the purity, but the identity of a selenium salt from supposedly reputable commercial suppliers [113]. Nor did they present results for the same compounds in the presence of $3 \%$ methanol (the title of the article is "Carbon-enhanced inductively coupled
TABLE 2: Relative signal intensities for continuous aspiration of standard solutions containing $1 \mu \mathrm{g} \mathrm{L}^{-1}$ arsenic as eight different species [92].

\begin{tabular}{lc}
\hline Species & Signal relative to arsenite (\%) \\
\hline Arsenite & 100 \\
Arsenate & 93 \\
MMA & 88 \\
DMA & 86 \\
Arsenobetaine & 81 \\
Arsenocholine & 78 \\
Trimethylarsine oxide & 78 \\
Tetramethylarsonium & 67 \\
\hline
\end{tabular}

plasma mass spectrometric detection of arsenic and selenium and its application to arsenic speciation"), which is a shame. However, they did show the sensitivities (expressed as counts per second per $\mu \mathrm{g} \mathrm{L}^{-1}$ As) for three species (DMA, arsenobetaine and arsenite) in 3\% methanol as a function of the aerosol carrier gas flow rate. It is quite obvious from these plots that (a) the highest sensitivity for each species is different (and not obtained for the same aerosol gas flow rate-though the extent of the compromise would probably be considered negligible, and (b) the species with highest sensitivity is DMA, followed by arsenobetaine (95\%) and arsenite (89\%). As has already been discussed above, Baba et al. [111] found that in $70 \%$ methanol the arsenite signal was only $28 \%$ that of for the same concentration of arsenic as MMA.

There is some evidence that compound-dependent responses can have their origin in the aerosol fractionation and transport systems, particularly when ultrasonic devices with associated vapor removal devices are employed. For example, Gammelgaard and Jøns [114] report no sensitivity differences for selenium species when using pneumatic nebulization, but signal enhancement for selenate and trimethylselenonium when introduced via an ultrasonic nebulizer and membrane desolvator. The use of a direct injection nebulizer should overcome all such effects (as the aerosol is created directly at the base of the plasma). However, quite marked compound-dependent effects are reported (without comment) by Brennan et al. [46]. Unlike many researchers, they were careful to report a number of analytical figures of merit for each species including (a) the sensitivity that is, the slope of the calibration, and (b) the solution detection limits. These two parameters are shown in Table 3 for the usual four arsenic species and para-arsanilic acid (a constituent of some animal feeds).

Interestingly, the species with the highest sensitivity (arsenite) had the worst detection limit, and one of the species with the lowest sensitivity (arsenate) had the best detection limit. This strongly suggests that the reproducibility (noise) for each peak was different; arsenite was eluted first at from about 4-5 min and arsenate eluted later from about 7 to 8 minutes. The intervening peaks for DMA and MMA were not completely resolved and the first peak for arsenite does show some tailing, so it may be that chromatographic features are responsible for the variation in the noise that in turn is 
TABLE 3: Figures of merit for five arsenic species separated by nanoHPLC followed by ICP-MS detection with high efficiency direct injection nebulization [46].

\begin{tabular}{lcccccc}
\hline Figure of merit & Arsenite & DMA & MMA & Arsenate & p-ASA \\
\hline Sensitivity counts $\mathrm{pg}^{-1}$ As & 40 & 24 & 17 & 17 & 19 \\
Limit of detection $\mu \mathrm{g} \mathrm{L}^{-1}$ & 110 & 53 & 54 & 8 & 88 \\
\hline
\end{tabular}

responsible for the rather remarkable more-than-one-orderof-magnitude difference in the detection limits.

In 2006, Yu et al. reported a difference in response in both plasma emission and plasma mass spectrometry for arsenite and arsenate [115] with the arsenite response being about $90 \%$ of that of arsenate. They are unable to offer any explanation other than "it must have occurred between [the] steps of aerosol transportation from the spray chamber to the plasma, droplet desolvation and vaporization near or within the plasma, and analyte atomization in the plasma." More recently Narukawa et al. have offered the explanation of "incoherent molecular formation" [116], which is hard to follow; but the basic idea is that not all of the precursor species introduced to the plasma in the aerosol are converted to atoms, some form molecular species (such as $\mathrm{AsO}$, and $\mathrm{AsH}$ ). The fraction of the analyte that travels through the plasma as these molecular species depends on the nature of the original compound-at least in the case of arsenic; the researchers do not observe the effect when comparing the sensitivities for selenite and selenate.

Larsen and Stürup [110] point out the potential for systematic error when total arsenic is determined by calibration against standards containing arsenic in a species different from that of the analyte, but indicate that this should not be a problem for speciation analysis as "quantification is carried out against standard curves prepared from each arsenic species individually, whereby this possible systematic error has been eliminated."

5.1.3. Chromatographic Separation. The next stage to consider in the process of examining methodology for arsenic speciation, in the reverse order in which the various stages are linked in a real method, is the chromatographic separation. Even if only the last 10 years or so is considered, there are a large number of research articles describing the HPLC separation of arsenic species in environmental samples. It is not surprising that the topic has been reviewed from a number of angles. As mentioned above, Popp et al. [45] have covered the past ten years' worth of major developments in environmental speciation analysis involving chromatography (liquid or gas) and ICP-MS detection. They highlight the emergence of isotopically enriched species specific standard materials (for mercury and tin determinations) as a major development and point out that the ability of MS to distinguish between isotopes has a number of applications in tracer studies. As an aside, it is unlikely that species-specific isotope dilution can be routinely applied to arsenic determinations as, although isotopes ranging from ${ }^{67}$ As to ${ }^{86}$ As are known, the longest lived isotope $\left({ }^{73} \mathrm{As}\right)$ has a half-life of only 80 days, Fewer than 20 articles are discussed in the "arsenic" section and the focus is more on applications, which is how the review is titled (rather than methodology) in particular to the analysis of waters and on the study of possible sources of arsenic release into the environment such as pressure-treated wood (in Florida) and the former kelp-related activities (on remote islands in northern Scotland). A 2012 article [117] entitled "Trace element speciation in food: State of the art of analytical techniques and methods" provides a rather superficial survey of the arsenic in food situation (only twelve references are cited, several of which report work that is 10 years old). However, the writers do make the critical observation that for the rice work a "certified reference material would be of benefit."

It is probably true that a majority of published descriptions of arsenic speciation feature separation by ion-exchange chromatography, and that the vast majority of these are anionexchange separations. Most of the most commonly looked for species and certainly the four in rice, are all water soluble weak acids of considerably different $\mathrm{pK}_{a}$ values, and thus the chromatography can be controlled by suitable choice of mobile phase $\mathrm{pH}$ and "buffer components." The application of ion-exchange chromatography has been comprehensively surveyed by Ammann in a 2011 article [118], which is recommended reading. There are useful summary tables, and the text contains an authoritative discussion of the role of composition of the mobile phase, especially those containing phosphate. Despite the title, the reviewer does include discussion of "ion-pair" chromatography, a technique that he considers to be problematic because the dynamic exchange capacity is affected by the sample matrix. Even though some researchers [119] have found "no ion pairing affect at all," it is pointed out that ion-pairing reagents can increase substantially the efficiency of ion-exchange separations, and therefore there are conditions under which the effect clearly exists. Interestingly, of the 51 articles selected for inclusion in the tables, only one is about the analysis of rice.

It should be borne in mind that chromatographic separation techniques dilute the analyte species considerably, placing extra demands on the instrument detection capability. If $50 \mu \mathrm{L}$ of a sample solution injected into an HPLC column elutes in a peak of base width $30 \mathrm{~s}$ at $1 \mathrm{~mL} \mathrm{~min}^{-1}$, then the average dilution is 10-times. As the analyte is not distributed uniformly across the peak, the dilution at the peak maximum is less: 5 times for an isosceles triangular peak. On the other hand, later eluting peaks (often the case for arsenate) may have a wider basewidth of, say $1 \mathrm{~min}$, with proportionately higher dilution at the peak maximum. The presence of other sample components can affect the peak shape. For example, Guzmán Mar et al. [74] show that the peak for DMA in a sample of NIST certified reference material 1568a rice flour has a basewidth of about $90 \mathrm{~s}$, whereas the peak for a $5 \mu \mathrm{g} \mathrm{L}{ }^{-1}$ arsenic standard (as DMA) is about $30 \mathrm{~s}$. Based on their analysis of this material, the arsenic content as DMA of the solution injected was about $4 \mu \mathrm{g} \mathrm{L}^{-1}$.

For the particular determination of arsenic species in rice, there is no agreement on the HPLC separation to use, certainly both reversed-phase ion-pair and ion-exchange chromatography have been featured in recent reports of this 
particular analysis. Unlike the situation for some determinations (where one species is present in vast excess over the others), the elution order is probably not a critical feature of the separation. For many chromatographic separations, arsenate is the last component to elute and thus is a major factor in the overall time for the analysis. Many sample preparation stages can handle multiple samples in parallel, but determination of species by HPLC-ICP-MS is a slow sequential analytical procedure. As has been discussed above, variations in the mobile phase composition can induce "compound-dependent" responses, and so gradient elution is probably a less desirable strategy than, say, increasing the flow rate after the early eluting species have been separated. It is also important to examine whether the first species to elute, often arsenite, is simply running in the void volume (or with the solvent front-that is, in not retained at all by the stationary phase). This is likely if the $\mathrm{pH}$ of the mobile phase is such that arsenite exists in aqueous solution as the fully protonated species $\mathrm{H}_{3} \mathrm{AsO}_{3}$. The danger, as pointed out by Hansen et al. [87], is that other nonretained species, such arsenobetaine will co-elute and cause a systematic error. Hansen et al. found tetramethylarsonium (a cation) in rice and Mandal et al. report the presence of arsenobetaine [120], that might, in fact, have been tetramethyarsonium [87], as no definitive identification by organic mass spectrometry was made. Some researchers prefer to oxidize all of the arsenite in the sample extract to arsenate, which can be readily done without altering other speciation by the addition of hydrogen peroxide [87]. This has at least two beneficial effects: it combines all the inorganic arsenic into one peak with the associated gain in sensitivity, detection capability and precision, and it removes arsenite from the front of the chromatogram allowing other species to be detected. If the goal is to determine the inorganic content of the sample, as might well be the case in the analysis of rice taken from a supermarket shelf, then no information is lost as a result of the peroxide oxidation. On the other hand it, is clearly possible to find conditions under which arsenobetaine and arsenite are baseline resolved at the front of the chromatogram [82] though arsenate was not completely eluted until 9 minutes had elapsed. Narukawa and Chiba describe [121] conditions for ion-pair chromatography under which arsenate eluted first followed by arsenite, MMA, DMA and arsenobetaine, in that order. The mobile phase contained butanesulfonate, tetramethylammonium hydroxide and malonate at $\mathrm{pH} 3$, so it is a little difficult to decide which reagent might be forming ion pairs and which might be dynamically coating the C18 stationary phase. Malonate has been found to be a good substitute for phosphate, which, as pointed out by Raber et al. [88], has a number of drawbacks, including salt-buildup and/or damage to the cones in the plasma mass spectrometer interface and incompatibility with organic MS ionization modes, notably electrospray ionization. They reported separation of MMA, DMA, and arsenate (arsenite was oxidized) in less than $4 \mathrm{~min}$ with a mobile phase consisting of $10 \mathrm{mM}$ malonic acid adjusted to $\mathrm{pH} 5.6$ with aqueous ammonia. The column was maintained at $40^{\circ} \mathrm{C}$, but the role of the temperature of the separation was not discussed.
Although it may appear that the separation stage is independent of the sample preparation, the residual matrix components that are introduced to the column along with the analytes can be problematical. Yuan et al. [122] report that organic matter present in the sample matrix (rice straw) can cause loss of resolution and damage to the column. They investigated three possible clean up procedures following the extraction (C-18, activated charcoal, and hexane extraction) and found that passage through a column containing $200 \mathrm{mg}$ of C-18 material was the best, even though about $10 \%$ of the DMA in the extract was retained. Similar problems were encountered by Narukawa and Chiba [121] in the analysis of rice. They also found a tendency for the peaks to broaden as the number of injections increased, and they attributed poor precision to the viscosity of the extract and adopted internal standardization with arsenobetaine as the internal standard, which, as discussed above, eluted last. No cleanup was employed, other than centrifugation and filtration.

The development of HPLC procedures for separating the limited number of arsenic species in rice is probably only a minority of the publications describing work in which arsenic species have been separated by the HPLC. There are, for example, 95 articles in the web of science database that are retrieved by entering the search terms arsen ${ }^{*}$ and urine and (anal* or deter*) in the "title" field. There are probably more articles describing speciation in waters; substituting "water" for "urine" in the search terms returns 378 hits, but not all the articles are concerned with the analysis of water. Adding the term "speci*", decreases the count to 70. Substituting "sea* or alg*" for "urine" in the original search, returns another 94 articles, many of which are concerned with speciation analysis. Removing the terms "anal* or deter" " from the key words and thereby broadening the search to reports of that do not necessarily feature analytical method development, increases the numbers of hits. For example searching for "arsen ${ }^{*}$ and (soil or sed ${ }^{*}$ ) and speci*" in the title field returns 168 hits; adding "anal" or deter", decreased the number to 24.

A detailed analysis of the state of the HPLC separation for the arsenic species in waters, urine, soils, sediments, and seafood is beyond the scope of the present review, but it is quite likely that the situation is the same as for the procedures described for the separation of the arsenic species in rice. There does not seem to be any convergence in the methodology. Part of the problem is that researchers often do not (a) explain what is new in their procedure, (b) cite any previous work on which their chromatographic separation is based, (c) describe what deficiencies of the existing methods they are setting out to redress, and (d) give chromatographic figures of merit.

5.2. Sample Preparation. Unlike the situation for the HPLC separation, it is possible that researchers are converging on a suitable sample pretreatment for the extraction of the four arsenic species in rice. It is taken as a given that the extraction of all the arsenic compounds into a solution by some relatively mild chemical procedures is a valid start to the determination of the arsenic species of relevance in rice. However, it should be borne in mind that what is measured is what appears 
in solution after the appropriate chemical reactions have taken place and the appearance of these four species does not necessarily tell us anything about the chemical species that are present in the solid rice grain. For those scientists interested in the rice as a food stuff, this is probably not a concern as the impact of rice consumption is felt through the compounds that are released and absorbed on passage of cooked rice through the stomach and gastro-intestinal tract. This is a separate area of scientific investigation, though one that might well be supported by reliable speciation analysis. It appears as though anything between $50 \%$ and $95 \%$ of the arsenic in the grain is bioaccessible $[123,124]$. Current thinking in terms of risk assessment would appear to be that the bioavailability should be considered $100 \%$ [125]. On the other hand, scientists interested in unraveling the biochemical mechanisms by which arsenic compounds are mobilized from the soil, transported through the roots, shoots and eventually deposited in the grain probably do need information about the compounds present in the grain itself. Solid state speciation is a much harder analytical problem, as most techniques that are capable of detecting elements in bulk solids (such as X-ray fluorescence spectrometry) are incapable of determining the speciation, so the approaches typically involves very high intensity X-rays (obtained from a synchrotron source) and interpretation of the fine structure in the absorption or emission spectra in terms of the identity of the neighboring atoms, coupled with sectioning of the grain. The establishment of the location and speciation of arsenic within the edible rice grain is considered "essential for understanding the risk [associated with the consumption of carcinogenic inorganic arsenic] and for developing effective strategies to reduce grain arsenic concentrations" [126]. This statement is taken from the abstract of a 2012 review of the relevant methodology for solid state speciation of arsenic (and selenium and germanium) in rice grain that appeared as part of the April 2012 issue of Analytical and Bioanalytical Chemistry devoted to elemental imaging and speciation in plant science. The "issue" consisted of an editorial, 4 reviews, 4 original papers, 1 technical note and 1 erratum [127] (the writers of [126] had forgotten to include details of the various grants and agencies that have been supporting their work).

There is a very large number of sample preparation procedures possible and probably every combination of reagent(s) and method of delivering some energy to the sample has been investigated. Although it is not easy to find a journal article in which the researchers present results to prove that arsenic is lost from rice grain on heating, the usual way of drying to determine the moisture content, there would appear to be agreement that the analysis should be performed on the material "as received" and the results corrected for moisture content determined in a separate experiment. For example, participants in IMEP-107 described above [95], were specifically told not to analyze the material after drying. As the moisture content can be as high as $14 \%$ [96], there would appear to be no question that results should be reported on a dry weight basis. There is also agreement that the particle size is important and that the material should be ground. Narukawa and Chiba [121] present results showing that, at least for their extraction conditions, grains should be ground to less than $150 \mu \mathrm{m}$. It is also known that (a) rice grain is not uniformly hard and (b) arsenic species are not uniformly distributed throughout the grains, so grinding and sieving to exclude larger particles is also not a sensible procedure. Sieving may well be necessary to ensure that all particles are below the target size. Narukawa et al. have also clearly shown [57] that in the case of brown rice, a significant fraction of the inorganic arsenic is in the bran (outer layer) and that even only removing $10 \%$ of the layer decreases the inorganic arsenic content of the remaining material to $60 \%$ of the original concentration. Thus it is important that the bran layer is also ground and included in the sample taken for analysis.

What has been described as the "classical water-methanol extraction" methods [84] have been thoroughly examined by Narukawa et al. [71], who studied the effectiveness of multiple water-methanol mixtures together with shaking, ultrasonication (bath), accelerated solvent extraction, or micro-wave assisted extraction. They concluded that microwave extraction at $80^{\circ} \mathrm{C}$ for $30 \mathrm{~min}$ with pure water and a sample: water ratio of $1: 10$ by weight was quantitative for all species. In a later paper [121], they argue that as "the microwave extraction system has low versatility, and skill is necessary to achieve consistently accurate results," a simple heating block method is needed. They found that with the heating block, the temperature needed to be raised to $90^{\circ} \mathrm{C}$ and the time increased to $3 \mathrm{~h}$. The sample, mass $1 \mathrm{~g}$, was heated with $10 \mathrm{~mL}$ of water in a $50 \mathrm{~mL}$ capped polypropylene centrifuge tube. Following heating, the sample was centrifuged and ( $4000 \mathrm{rpm}$ for $5 \mathrm{~min}$ ) and filtered ( $0.45 \mu \mathrm{m}$ PDVF membrane).

Heating blocks were also preferred over microwave ovens by Huang et al. [128] in their study of the extraction by a variety of reagents, including, acids, bases and the enzyme amylase (which catalyzes the hydrolysis of $\alpha-1,4$ glucosidic linkages in starch). They concluded that nitric acid alone at a concentration of $0.28-0.7 \mathrm{M}$ (at $95^{\circ} \mathrm{C}$ and $90 \mathrm{~min}$ ) extracted all arsenic species without redox transformation. They attributed this to a balance between the oxidizing ability of the nitric acid and the reducing ability of thiolate compounds also released during the extraction. This method was adapted by Batista et al. [82] for the speciation analysis of Brazilian rice. Huang et al. have recently applied their procedure to the analysis of NIST 1568a as well as a number of other reference materials and 121 real samples involving 12 types of rice grain [91].

Some researchers have coupled the nitric acid extraction with deliberate oxidation of arsenite to arsenate by the addition of hydrogen peroxide [76], for reasons that were discussed above. Raab et al. described a procedure in which arsenic species were extracted with " $1 \%$ Aristar nitric acid and $1 \%(\mathrm{vol} / \mathrm{vol})$ hydrogen peroxide suprapur." No reagents are listed in the paper, so it is not clear what concentration the original hydrogen peroxide solution was; as concentrated nitric acid is $16 \mathrm{M}$, it may be deduced that $1 \%$ nitric acid is $0.16 \mathrm{M}$. This procedure is described without citation to any earlier publication, and when "validated" by the speciation analysis of NIST 1568a gave values for the inorganic and organic arsenic contents that "compare favorably with previously reported values." Spike recoveries for DMA and arsenate were slightly high and not significantly different 
from $100 \%$, respectively. Unfortunately, these results could not be replicated by Alava et al. [90], who found "remarkable interspecies conversions" and presented results showing not only had arsenite not been oxidized to arsenate but that very substantial amounts of DMA had been converted to the other species, but mostly to arsenate. They also investigated the $0.28 \mathrm{M}$ nitric method of Huang et al. [128] and concluded that it gave the same results as for a hot water extraction, and so they endorsed the method originally described by Narukawa et al. [71] (sealed vessel in microwave, $1: 10$ rice to water mass ratio, $80^{\circ} \mathrm{C}$ for $30 \mathrm{~min}$ ).

As an alternative to nitric acid, trifluoracetic acid (TFA) has been proposed as long ago as 2001 [58] and was recently investigated along with nitric acid and ammonia as extractants by Raber et al. [88]. They tested three different concentrations of each reagent $(0.02,0.1$, and $1 \mathrm{M})$ and found that quantitative extraction of arsenic species could be obtained with $0.02 \mathrm{M}$ TFA; they also found that the addition of $1 \%$ hydrogen peroxide (made from a 30\% solution) caused complete oxidation of arsenite to arsenate, but that there was "no significant degradation of organic arsenicals to arsenate." This claim is not entirely supported by the results presented for the analysis of NIST SRM 1568a: with TFA alone, the DMA content found is $200 \pm 12 \mu \mathrm{g} \mathrm{kg}^{-1}$ and the inorganic arsenic is $79 \pm 7 \mu \mathrm{g} \mathrm{kg}^{-1}$; when the peroxide is added, the DMA content found is $166 \pm 2 \mu \mathrm{g} \mathrm{kg}^{-1}$ and the inorganic arsenic is $96 \pm 1 \mu \mathrm{g} \mathrm{kg}^{-1}$. The \pm terms are one standard deviation for $n=3$, so the $95 \%$ confidence intervals are such that the difference between the DMA values is significant at the $95 \%$ level; whereas, the difference between the inorganic arsenic values may not be significant.

If the method is also to be applied to other food stuffs or to other analytes (notably selenium species) then methods involving enzyme catalyzed hydrolysis are preferred. Guzmán Mar et al. extracted simultaneously the arsenic and selenium species from rice products by a microwave-assisted $\left(37^{\circ} \mathrm{C}\right.$ for $40 \mathrm{~min}$ ) procedure catalyzed by the enzymes protease XIV and $\alpha$-amylase [74]. The procedures appeared to work for the arsenic species, but not all of the selenium species were solubilized. It appears as though there are problems with enzyme purity. Guzamán Mar et al. report that they selected values of $50 \mathrm{mg}$ of protease XIV and $25 \mathrm{mg}$ of $\alpha$-amylase as a compromise between satisfactory extraction recovery and "reduction of the levels of As(V) in the procedural blank." Dufailly et al. [84] resorted to the purification of the same enzymes prior to use in a method for the speciation of arsenic compounds in food (rice, baby food, mussel, milk powder, soya four, tuna, and seaweed flakes). They used ultrasonic agitation with a probe operated at about $80 \mathrm{~W}$ for $5 \mathrm{~min}$ to extract the species. This ultrasonic probe plus mixed enzyme-catalyzed hydrolysis was first described by Sanz et al. [64] for the preparation of rice samples for arsenic speciation analysis and adapted shortly after, by them, for the extraction of arsenic species from chicken muscle, fish tissue and soil. It would appear to be significantly faster than other procedures, but may not completely solubulize all the arsenic species [65]. The procedure was modified slightly by Tsai and Jiang [83], who increased the temperature to $70^{\circ} \mathrm{C}$ (for $30 \mathrm{~min}$ ) as a strategy "to improve the extraction efficiency of selenium species." This is presumably below the temperatures at which the enzymes are denatured, but this was not discussed in the article. As it turned out, the sum of selenium species extracted, $225 \pm 3 \mu \mathrm{g} \mathrm{kg}^{-1}$, was less than the $303 \pm 9 \mu \mathrm{g} \mathrm{kg}^{-1}$, extracted by Guzmán Mar et al. [74]. Not only that but the two research groups reported rather different values for the selenomethionine content: $210 \pm 3$ and $303 \pm 9 \mu \mathrm{g} \mathrm{kg}^{-1}$, respectively. It is possible that there are similar problems with the speciation of selenium compounds in foodstuffs as have been discussed in this review, but that is, fortunately, a topic that is outside the scope of the present discussion. It is worth noting that the TFA and peroxide procedure described by Raber et al. [88] was also applied to the analysis of wheat and tuna fish (for the arsenic species) and that Llorente-Mirandes et al. [89] determined arsenic species in rice and rice products by a method which powdered samples were heated together with $0.2 \%$ nitric acid and $1 \%$ hydrogen peroxide in a microwave system at $95^{\circ} \mathrm{C}$ and $45 \mathrm{~min}$ (followed by centrifugation and filtration through $0.45 \mu \mathrm{m}$ PET membranes, both of which seem to be standard in most procedures).

\section{Concluding Remarks}

It is should be pointed out given the fairly intense scrutiny of the arsenic compounds in rice by the US FDA in the wake of the Consumer Reports article, that there is, (despite one or two recent suggestions to the contrary $[67,91])$ a rice reference material that is certified for the arsenic speciation. It is NMIJ CRM 7503-a, arsenic compounds, and trace elements in white rice flour, prepared by the National Metrology Institute of Japan and available from at least one chemical supply house in the US (Wako Chemical Inc). Also, at the time of writing, the NIST material (SRM 1568a) is not available (out of stock), but it will shortly be reissued after further processing [129]. The wheat flour material, SRM $1567 \mathrm{a}$, is also out of stock. The NMIJ material contains $71 \pm$ $3 \mu \mathrm{g} \mathrm{kg}^{-1}$ arsenite, $13.0 \pm 0.9 \mu \mathrm{g} \mathrm{kg}^{-1}$ arsenate, and $13.3 \pm$ $0.9 \mu \mathrm{g} \mathrm{kg}^{-1}$ DMA (total $97 \mu \mathrm{g} \mathrm{kg}^{-1}$ ). The \pm terms are described as expanded uncertainties determined with a coverage factor of $k$ equal to 2, corresponding to "an estimated confidence interval of approximately 95\%." The certificate is dated August 2009. In addition to the analysis of a reference material certified for the arsenic species content, method validation should include the measurement of the recovery of spikes added as early as possible in the method.

The data reported for the analysis of the NIST 1568a material shown in Table 1 supports the calculation that the inorganic arsenic content is $94 \pm 4 \mu \mathrm{g} \mathrm{kg}^{-1}$ and the DMA content is $163 \pm 7 \mu \mathrm{g} \mathrm{kg}^{-1}$, (even including the probable outlier of $239 \mu \mathrm{g} \mathrm{kg}^{-1}$ ), where the \pm terms are, in fact, the $95 \%$ confidence intervals. So this material was quite different from the currently available NMIJ material in terms of the organic arsenic content, but does contain a similar amount of inorganic arsenic. It is likely that the NIST material was made from "unpolished" or "brown" rice.

Assuming that NIST releases another rice flour reference material and even if it is certified for the arsenic speciation, 
it is likely that publications describing its analysis (as part of method validation strategy) are going to continue to appear. It would be very helpful to the relevant sectors of the analytical chemistry community if all the relevant details are disclosed in the description of the method optimization and validation. These would include details of grinding (what was the final maximum particle size and how was it measured) and drying and clarification of whether the dried sample was analyzed, and if it was (as is strongly suggested in some recent reports [90]) whether there was any evidence of loss of analytes at this stage. The conflicting results concerning species transformation as a result of the addition of hydrogen peroxide need to be resolved and, if the hot water extraction is to be recommended, the possible interferences with the chromatography due to the presence of starch material that is also extracted but not hydrolyzed should be investigated. Any method that is developed should be capable of dealing with large numbers of samples without undue damage to or degradation of the HPLC column.

It should be clear what the history of the HPLC separation is, and if it is new, what experiments were performed to optimize the separation and what the figure(s) of merit was/ were. If the chromatography is not new, the previous work on which it is based should be cited. It is well known that it is not possible to maximize both resolution and speed of analysis (retention time of the last peak). Information about plate numbers, resolution and peak asymmetry should be provided, so that it is readily possible to compare one chromatographic separation with another. It is also well known that not all notionally identical HPLC columns are in fact the same, and, as manufacturers continue to introduce new (and no doubt improved) columns, there will be a continued publication of separations with these new columns. Researchers should investigate compounddependent responses and provide calibration data for each species. The use of "supplemental information" (provided free by almost all journals these days) as a means of disseminating such information, possibly even as data files, is to be encouraged. All relevant information, such as sample volume, flow rate, column dimensions, use of guard column, and temperature, should be included. It should be clear whether the separation was isocratic or whether a gradient was involved and if it was, how was the column equilibrated for the next sample (and how long did it take?). The fate of chloride in the system should be clearly shown and, if there is likely to be a problem with the formation of ${ }^{40} \mathrm{Ar}^{35} \mathrm{Cl}^{+}$, the strategy to overcome this interference should be stated. It should be clear where the solvent front is and whether the first component to be eluted is running with the solvent front or not. The effects of carbon, either deliberately added to the mobile phase or plasma to enhance ionization efficiency, or carried through the procedure as the result of the digestiondissolution methodology need to be evaluated and if necessary, taken into account. This seems likely to be a feature of food analysis for the foreseeable future even for total element determinations, as complete digestions, such as could be obtained with perchloric acid, are not possible. Clearly for speciation analysis, the relatively mild extraction conditions needed to prevent species interconversion are likely to solubilize considerable amounts of organic material, especially if reagents capable of hydrolyzing the bonds between the subunits of the relevant biopolymers are involved. Larsen set out a set of general recommendations for the optimization and validation speciation analysis by HPLC-ICP-MS that are still as valid today as when they appeared in a special issue of Spectrochimica Acta Part B on speciation in 1998 [130].

There is likely to be an increasing interest in the application of ultraperformance liquid chromatography (UPLC) as such systems become more widely available and possibly in alternative separation modes, such a hydrophilic interaction chromatography (HILIC). Although not a constraint for the "routine" determination of inorganic arsenic species in rice, the need to elute separated components into an organic mass spectrometer for qualitative analysis via an ionization source such as electrospray ionization (ESI) places restrictions on the components of the mobile phase. The continuing search for, and identification of, arsenic compounds in foods (and other materials such as plants with potential for phytoremediation) will be considerably helped by the simultaneous collection of data from an ICP-MS instrument and an ESI instrument [131]. Several research laboratories around the world have such HPLC detectors set up parallel; for example, the Aberdeen group have identified new arsenolipids in fish tissue with such a system [132], and there is even one research group, (Hieftje, Indiana) working on the construction of an instrument consisting of one mass spectrometer with dual ICP, ESI inlets $[133,134]$.

It is also possible that some of the problems encountered in the ongoing proficiency tests could be overcome if laboratories were to report realistic uncertainties based on replicate analysis of separate solid samples, rather than, say, replicate measurements of the same digest. It should also be borne in mind that for small numbers of replicates, the $95 \%$ confidence interval about the mean is much larger than \pm one standard deviation. For example for $n=3$, the $95 \%$ confidence interval is \pm 2.5 times the standard deviation. It should be noted that the literature results for the sum of species in NIST 1568a is $269 \pm 8 \mu \mathrm{g} \mathrm{kg}^{-1}$ (mean $\pm 95 \%$ confidence interval), an interval that definitely does not include the mean of the certificate value for the total arsenic of $290 \mu \mathrm{g} \mathrm{kg}^{-1}$. Fortunately, the expanded uncertainty (approximately 95\% confidence interval) for this value of $\pm 30 \mu \mathrm{g} \mathrm{kg}^{-1}$ does include the mean of the experimental values, and thus it is likely that the means are not significantly different. Despite that fact that every result (except four, one of which is probably an outlier) is less than the certificate value, there is no statistical evidence, based on the $t$-test, to support the hypothesis that methods are biased low. Were the \pm term for the NIST material to be $\pm 20 \mu \mathrm{g} \mathrm{kg}^{-1}$, a value more in line with the numbers for the NMIJ material $\left(98 \pm 7 \mu \mathrm{g} \mathrm{kg}^{-1}\right)$, then there would be a significant difference between the certificate value and the average of the sum of species.

One final note concerns sample homogeneity. The data presented by the Consumer Reports article [33] for the inorganic and total arsenic in rice and rice products includes values for different lots from the same supplier. For example, 
the three lots of "Rice Select Organic Texmati" white rice contained 330, 448, and $917 \mu \mathrm{g} \mathrm{kg}^{-1}$ total arsenic and 84, 106 , and $102 \mu \mathrm{g} \mathrm{kg}^{-1}$, respectively of inorganic arsenic, corresponding to 25,24 and $11 \%$ inorganic arsenic respectively. "Martin Long Grain" brown rice did not have lot codes on the product, and four separate samples were tested, two from each of two on-line purchases of the product. The total arsenic concentrations found were $398,455,143$, and $113 \mu \mathrm{g} \mathrm{kg}^{-1}$; the inorganic arsenic concentrations were 214, 211, 82, and $84 \mu \mathrm{g} \mathrm{kg}^{-1}$, respectively corresponding $54,46,58$ and $74 \%$ of inorganic arsenic. There are no details provided of how the samples were taken from the bags of rice, a comment that also applies to most of the reports in the analytical literature of the determination of arsenic species in rice. The only information provided is typically that, after grinding, a relatively small sample mass ( $\mathrm{g}$ or less) is taken for analysis. The Consumer Reports data makes it clear that probably not all bags of a given product have the same arsenic speciation. This raises the question of how homogeneously the species are distributed in any particular bag. It is probably important that laboratories that will be measuring arsenic species in rice taken from the supermarket shelves ensure that the subsample of grains taken for analysis is representative of the entire bag.

\section{Acknowledgment}

The help of Dr. Tiffany Berg in the preparation of this paper is gratefully acknowledged.

\section{References}

[1] S. Ahuja, Ed., Arsenic Contamination of Groundwater: Mechanism, Analysis and Remediation, John Wiley \& Sons, Hoboken, NJ, USA, 2008.

[2] K. R. Henke, Ed., Arsenic Environmental Chemistry, Health Threats and Waste Treatment, John Wiley \& Sons, Chichester, UK, 2009.

[3] R. Ravenscroft, H. Banner, and K. Richards, Arsenic Pollution, A Global Synthesis, Wiley-Blackwell, Chichester, UK, 2009.

[4] A. A. Meharg, Venomous Earth, How Arsenic Caused the World's Worst Mass Poisoning, Macmillan, Basingstoke, UK, 2005.

[5] W. R. Cullen, Is Arsenic An Aphrodisiac? the Sociochemistry of An Element, Royal Society of Chemistry, Cambridge, UK, 2008.

[6] P. K. Dasgupta, “Editorial," Talanta, vol. 58, no. 1, pp. 1-2, 2002.

[7] B. K. Mandal and K. T. Suzuki, "Arsenic round the world: a review," Talanta, vol. 58, no. 1, pp. 201-235, 2002.

[8] Kaye and Laby, "Table of Physical and Chemical Constants," January 2012, http://www.kayelaby.npl.co.uk/chemistry/3_1/3_ 1_3.html.

[9] CRC Handbook of Chemistry and Physics, CRC Press, 92nd edition, 2011.

[10] H. Haraguchi, "Metallomics as integrated biometal science," Journal of Analytical Atomic Spectrometry, vol. 19, pp. 5-14, 2004.

[11] W. R. Cullen, "Arsenophobia: a connection between the deaths of infants and Napoleon I," in Is Arsenic an Aphrodisiac? The Sociochemistry of an Element, pp. 145-161, Royal Society of Chemistry, Cambridge, UK, 2008.
[12] A. Lugli, I. Zlobec, G. Singer, A. K. Lugli, L. M. Terracciano, and R. M. Genta, "Napoleon Bonaparte's gastric cancer: a clinicopathologic approach to staging, pathogenesis, and etiology," Nature Clinical Practice Gastroenterology and Hepatology, vol. 4, no. 1, pp. 52-57, 2007.

[13] H. Garelick and H. Jones, Eds., Reviews of Environmental Contamination, vol. 197 of Reviews of Environmental Contamination and Toxicology, Springer, 2002.

[14] H. Garelick, H. Jones, A. Dybowska, and E. Valsami-Jones, "Arsenic pollution sources," Reviews of Environmental Contamination and Toxicology, vol. 197, pp. 17-60, 2008.

[15] M. M. Rahman, F. Rahman, L. Sansom, R. Naidu, and O. Schmidt, "Arsenic interactions with lipid particles containing iron," Environmental Geochemistry and Health, vol. 31, no. 1, pp. 201-206, 2009.

[16] M. M. Rahman, R. Naidu, and P. Bhattacharya, "Arsenic contamination in groundwater in the Southeast Asia region," Environmental Geochemistry and Health, vol. 31, no. 1, pp. 9-21, 2009.

[17] N. I. Khan, G. Owens, D. Bruce, and R. Naidu, "Human arsenic exposure and risk assessment at the landscape level: a review," Environmental Geochemistry and Health, vol. 31, no. 1, pp. 143166, 2009.

[18] M. M. Rahman, J. C. Ng, and R. Naidu, "Chronic exposure of arsenic via drinking water and its adverse health impacts on humans," Environmental Geochemistry and Health, vol. 31, no. 1, pp. 189-200, 2009.

[19] M. M. Rahman, Z.-L. Chen, and R. Naidu, "Extraction of arsenic species in soils using microwave-assisted extraction detected by ion chromatography coupled to inductively coupled plasma mass spectrometry," Environmental Geochemistry and Health, vol. 31, no. 1, pp. 93-102, 2009.

[20] F. Rahman, Z.-L. Chen, and R. Naidu, "A comparative study of the extractability of arsenic species from silverbeet and amaranth vegetables," Environmental Geochemistry and Health, vol. 31, no. 1, pp. 103-113, 2009.

[21] W. R. Cullen, "Arsenic where you least expect it," in Is Arsenic an Aphrodisiac? The Sociochemistry of an Element, p. 71, Royal Society of Chemistry, Cambridge, UK, 2008.

[22] H. F. Hemond and H. M. Solo-Gabriele, "Children's exposure to arsenic from CCA-treated wooden decks and playground structures," Risk Analysis, vol. 24, no. 1, pp. 51-64, 2004.

[23] J. S. Tsuji, L. J. Yost, L. M. Barraj, C. G. Scrafford, and P. J. Mink, "Use of background inorganic arsenic exposures to provide perspective on risk assessment results," Regulatory Toxicology and Pharmacology, vol. 48, no. 1, pp. 59-68, 2007.

[24] D. Amarasiriwardena, "Teaching analytical atomic spectroscopy advances in an environmental chemistry class using a project-based laboratory approach: investigation of lead and arsenic distributions in a lead arsenate contaminated apple orchard," Analytical and Bioanalytical Chemistry, vol. 388, no. 2, pp. 307-314, 2007.

[25] P. N. Williams, A. Raab, J. Feldmann, and A. A. Meharg, "Market basket survey shows elevated levels of as in South Central U.S. processed rice compared to California: consequences for human dietary exposure," Environmental Science and Technology, vol. 41, no. 7, pp. 2178-2183, 2007.

[26] B. Hua, W. G. Yan, J. M. Wang, B. L. Deng, and J. Yang, "Arsenic accumulation in rice grains: effects of cultivars and water management practices," Environmental Engineering Science, vol. 28, no. 8, pp. 591-596, 2011. 
[27] R. A. Schoof, L. J. Yost, J. Eickhoff et al., "A market basket survey of inorganic arsenic in food," Food and Chemical Toxicology, vol. 37, no. 8, pp. 839-846, 1999.

[28] A. A. Meharg and F.-J. Zhao, Arsenic \& Rice, Springer, Dordrecht, Germany, 2012.

[29] "European Food Safety Authority Panel on Contaminants in the Food Chain (CONTAM), scientific opinion on arsenic in food," EFSA Journal, vol. 7, p. 1351, 2009, http://www.efsa.europa.eu/.

[30] D. M. Meacher, D. B. Menzel, M. D. Dillencourt et al., "Estimation of multimedia inorganic arsenic intake in the U.S. population," Human and Ecological Risk Assessment, vol. 8, no. 7, pp. 1697-1721, 2002.

[31] J. Xue, V. Zartarian, S.-W. Wang, S. V. Liu, and P. Georgopoulos, "Probabilistic modeling of dietary arsenic exposure and dose and evaluation with 2003-2004 NHANES data," Environmental Health Perspectives, vol. 118, no. 3, pp. 345-350, 2010.

[32] A. A. Meharg and F.-J. Zhao, "Arsenic in rice grain," in Arsenic \& Rice, chapter 2, pp. 11-30, Springer, Dordrecht, Germany, 2012.

[33] Consumer Reports, "Arsenic in your food: our findings show real need for federal standards for this toxin," October 2012, http://www.consumerreports.org/cro/magazine/2012/11/arsenic-in-your-food/index.htm.

[34] "Joint FAO/WHO expert committee on food additives, seventysecond meeting, Rome, Italy," February 2010, summary and conclusions Issued 16th March 2010, http://www.who.int/foodsafety/chem/summary72_rev.pdf.

[35] US Department of Food and Agriculture, "Arsenic In Rice: Full Analytical Results From Rice/Rice Product Sampling," September 2012, http://www.fda.gov/forconsumers/consumerupdates/ucm319827.htm.

[36] K. A. Francesconi, "Toxic metals species and food regulationsmaking a healthy choice," Analyst, vol. 13, pp. 17-20, 2007.

[37] D. Gilbert-Diamond, K. L. Cottingham, J. F. Gruber et al., "Rice consumption leads to arsenic exposure in US women," Proceedings of the National Academy of Sciences of the United States of America, vol. 108, pp. 20656-20660, 2011.

[38] D. T. Heitkemper, K. M. Kubachka, P. R. Halpin, M. N. Allen, and N. V. Shockey, "Survey of total arsenic and arsenic speciation in us-produced rice as a reference point for evaluating change and future trends," Food Additives and Contaminants B, vol. 2, no. 2, pp. 112-120, 2009.

[39] A. A. Meharg and A. Raab, "Getting to the bottom of arsenic standards and guidelines," Environmental Science and Technology, vol. 44, no. 12, pp. 4395-4399, 2010.

[40] D. M. Templeton, F. Ariese, R. Cornelis et al., "Guidelines for terms related to chemical speciation and fractionation of elements. Definitions, structural aspects, and methodological approaches (IUPAC recommendations 2000)," Pure and Applied Chemistry, vol. 72, no. 8, pp. 1453-1470, 2000.

[41] K. A. Francesconi and D. Kuehnelt, "Determination of arsenic species: a critical review of methods and applications, 20002003," Analyst, vol. 129, no. 5, pp. 373-395, 2004.

[42] A. Gonzalvez, M. L. Cervera, S. Armenta, and M. de la Guardia, "A review of non-chromatographic methods for speciation analysis," Analytica Chimica Acta, vol. 636, no. 2, pp. 129-157, 2009.

[43] H. M. Anawar, "Arsenic speciation in environmental samples by hydride generation and electrothermal atomic absorption spectrometry," Talanta, vol. 88, pp. 30-42, 2012.

[44] A. D’Ulivo, J. Dědina, Z. Mester, R. E. Sturgeon, Q. Q. Wang, and B. Welz, "Mechanisms of chemical generation of volatile hydrides for trace element determination (IUPAC technical report)," Pure and Applied Chemistry, vol. 83, no. 6, pp. 12831340, 2011.

[45] M. Popp, S. Hann, and G. Koellensperger, "Environmental application of elemental speciation analysis based on liquid or gas chromatography hyphenated to inductively coupled plasma mass spectrometry-a review," Analytica Chimica Acta, vol. 668, no. 2, pp. 114-129, 2010.

[46] R. G. Brennan, S. A. E. O’Brien Murdock, M. Farmand et al., "Nano-HPLC-inductively coupled plasma mass spectrometry for arsenic speciation," Journal of Analytical Atomic Spectrometry, vol. 22, no. 9, pp. 1199-1205, 2007.

[47] I. Komorowicz and D. Barałkiewicz, "Arsenic and its speciation in water samples by high performance liquid chromatography inductively coupled plasma mass spectrometry-last decade review," Talanta, vol. 84, no. 2, pp. 247-261, 2011.

[48] B. Radke, L. Jewell, and J. Namiesnik, "Analysis of arsenic species in environmental samples," Critical Reviews in Analytical Chemistry, vol. 42, pp. 162-183, 2012.

[49] K. K. Kroening, R. N. Easter, D. D. Richardson, S. A. Willison, and J. A. Caruso, Analysis of Chemical Warfare Degradation Products, John Wiley \& Sons, New York, NY, USA, 2011.

[50] R. Cornelis, K. G. Heumann, J. Caruso, and H. Crews, Eds., Handbook of Elemental Speciation: Techniques and Methodology, John Wiley \& Sons, Chichester, UK, 2003.

[51] R. Cornelis, K. G. Heumann, J. Caruso, and H. Crews, Eds., Handbook of Elemental Speciation II: Species in the Environment, Food, Medicine and Occupational Health, John Wiley \& Sons, Chichester, UK, 2005.

[52] "Detection limits, Atomic Spectroscopy, A Guide to Selecting the Appropriate Technique and System, Perkin Elmer, p. 12," 2012, http://www.perkinelmer.com/Technologies/Atomic-Spectroscopy/cat1/NAV_04_TCH_Technologies_001/cat2/NAV_TCH_ Atomic\%20Spectroscopy_001.

[53] D. Sánchez-Rodas, W. T. Corns, B. Chen, and P. B. Stockwell, "Atomic fluorescence spectrometry: a suitable detection technique in speciation studies for arsenic, selenium, antimony and mercury," Journal of Analytical Atomic Spectrometry, vol. 25, no. 7, pp. 933-946, 2010.

[54] D. E. Mays and A. Hussam, "Voltammetric methods for determination and speciation ofinorganic arsenic in the environment-a review," Analytica Chimica Acta, vol. 646, pp. 6-16, 2009.

[55] J. H. T. Luong, E. Majid, and K. B. Male, "Analytical tools for monitoring arsenic in the environment," The Open Analytical Chemistry Journal, vol. 1, pp. 7-14, 2007.

[56] D. Q. Hung, O. Nekrassova, and R. G. Compton, "Analytical methods for inorganic arsenic in water: a review," Talanta, vol. 64, no. 2, pp. 269-277, 2004.

[57] T. Narukawa, A. Hioki, and K. Chiba, "Speciation and monitoring test for inorganic arsenic in white rice flour," Journal of Agricultural and Food Chemistry, vol. 60, pp. 1122-1127, 2012.

[58] D. T. Heitkemper, N. P. Vela, K. R. Stewart, and C. S. Westphal, "Determination of total and speciated arsenic in rice by ion chromatography and inductively coupled plasma mass spectrometry," Journal of Analytical Atomic Spectrometry, vol. 16, no. 4, pp. 299-306, 2001.

[59] I. Pizarro, M. Gómez, C. Cámara, and M. A. Palacios, "Arsenic speciation in environmental and biological samples: extraction and stability studies," Analytica Chimica Acta, vol. 495, pp. 8598, 2003. 
[60] U. Kohlmeyer, E. Jantzen, J. Kuballa, and S. Jakubik, "Benefits of high resolution IC-ICP-MS for the routine analysis of inorganic and organic arsenic species in food products of marine and terrestrial origin," Analytical and Bioanalytical Chemistry, vol. 377, no. 1, pp. 6-13, 2003.

[61] M. D’Amato, G. Forte, and S. Caroli, "Identification and quantification of major species of arsenic in rice," Journal of AOAC International, vol. 87, pp. 238-243, 2004.

[62] N. P. Vela and D. T. Heitkemper, "Total arsenic determination and speciation in infant food products by ion-chromatography inductively coupled plasma-mass spectrometry," Journal of AOAC International, vol. 87, no. 1, pp. 244-252, 2004.

[63] P. N. Williams, A. H. Price, A. Raab, S. A. Hossain, J. Feldmann, and A. A. Meharg, "Variation in arsenic speciation and concentration in paddy rice related to dietary exposure," Environmental Science and Technology, vol. 39, no. 15, pp. 5531-5540, 2005.

[64] E. Sanz, R. Muñoz-Olivas, and C. Cámara, "Evaluation of a focused sonication probe for arsenic speciation in environmental and biological samples," Journal of Chromatography A, vol. 1097, pp. 1-8, 2005.

[65] E. Sanz, R. Muñoz-Olivas, and C. Cámara, "A rapid and novel alternative to conventional sample treatment for arsenic speciation in rice using enzymatic ultrasonic probe," Analytica Chimica Acta, vol. 535, no. 1-2, pp. 227-235, 2005.

[66] A. H. Ackerman, P. A. Creed, A. N. Parks et al., "Comparison of a chemical and enzymatic extraction of arsenic from rice and an assessment of the arsenic absorption from contaminated water by cooked rice," Environmental Science and Technology, vol. 39, no. 14, pp. 5241-5246, 2005.

[67] S.-H. Nam, J. Cheng, W. R. Mindak, and S. G. Capar, "Preliminary results of extraction, separation and quantitation of arsenic species in food and dietary supplements by HPLC-ICP-MS," Bulletin of the Korean Chemical Society, vol. 27, no. 6, pp. 903908, 2006.

[68] E. Sanz, R. Muñoz-Olivas, C. Cámara, M. K. Sengupta, and S. Ahamed, "Arsenic speciation in rice, straw, soil, hair and nails samples from the arsenic-affected areas of Middle and Lower Ganga plain," Journal of Environmental Science and Health A, vol. 42, no. 12, pp. 1695-1705, 2007.

[69] M. Resano, E. García Ruiz, V. G. Mihucz, A. M. Móricz, Gy. Záray, and F. Vanhaecke, "Rapid screening method for arsenic speciation by combining thin layer chromatography and laser ablation-inductively coupled plasma-dynamic reaction cellmass spectrometry," Journal of Analytical Atomic Spectrometry, vol. 22, no. 9, pp. 1158-1162, 2007.

[70] M. N. Matos Reyes, M. L. Cervera, R. C. Campos, and M. de la Guardia, "Determination of arsenite, arsenate, monomethylarsonic acid and dimethylarsinic acid in cereals by hydride generation atomic fluorescence spectrometry," Spectrochimica Acta B, vol. 62, no. 9, pp. 1078-1082, 2007.

[71] T. Narukawa, K. Inagaki, T. Kuroiwa, and K. Chiba, "The extraction and speciation of arsenic in rice flour by HPLC-ICPMS," Talanta, vol. 77, no. 1, pp. 427-432, 2008.

[72] Y. G. Zhu, G. X. Sun, M. Lei et al., "High percentage inorganic arsenic content of mining impacted and nonimpacted chinese rice," Environmental Science and Technology, vol. 42, no. 13, pp. 5008-5013, 2008.

[73] A. Signes, K. Mitra, F. Burló, and A. A. Carbonell-Barrachina, "Contribution of water and cooked rice to an estimation of the dietary intake of inorganic arsenic in a rural village of West Bengal, India," Food Additives and Contaminants A, vol. 25, no. 1, pp. 41-50, 2008.
[74] J. L. Guzmán Mar, L. H. Reyes, G. M. M. Rahman, and H. M. S. Kingston, "Simultaneous extraction of arsenic and selenium species from rice products by microwave-assisted enzymatic extraction and analysis by ion chromatography-inductively coupled plasma-mass spectrometry," Journal of Agricultural and Food Chemistry, vol. 57, no. 8, pp. 3005-3013, 2009.

[75] G. X. Sun, P. N. Williams, Y. G. Zhu et al., "Survey of arsenic and its speciation in rice products such as breakfast cereals, rice crackers and Japanese rice condiments," Environment International, vol. 35, no. 3, pp. 473-475, 2009.

[76] A. Raab, C. Baskaran, J. Feldmann, and A. A. Meharg, "Cooking rice in a high water to rice ratio reduces inorganic arsenic content," Journal of Environmental Monitoring, vol. 11, no. 1, pp. 41-44, 2009.

[77] A. J. Signes-Pastor, C. Deacon, R. O. Jenkins, P. I. Haris, A. A. Carbonell-Barrachina, and A. A. Meharg, "Arsenic speciation in Japanese rice drinks and condiments," Journal of Environmental Monitoring, vol. 11, no. 11, pp. 1930-1934, 2009.

[78] M. K. Sengupta and P. K. Dasgupta, "An automated hydride generation interface to ICP-MS for measuring total arsenic in environmental samples," Analytical Chemistry, vol. 81, pp. 97379743, 2009.

[79] M.-K. Paik, M.-J. Kim, W.-I. Kim et al., "Determination of arsenic species in polished rice using a methanol-water digestion method," Journal of the Korean Society for Applied Biological Chemistry, vol. 53, pp. 8183-8188, 2010.

[80] Y. He and Y. Zheng, "Assessment of in vivo bioaccessibility of arsenic in dietary rice by a mass balance approach," Science of the Total Environment, vol. 408, pp. 1430-1436, 2010.

[81] T. Nishimura, M. Hamano-Nagaoka, N. Sakakibara, T. Abe, Y. Maekawa, and T. Maitani, "Determination method for total arsenic and partial-digestion method with nitric acid for inorganic arsenic speciation in several varieties of rice," Journal of the Food Hygienic Society of Japan, vol. 51, no. 4, pp. 178-181, 2010.

[82] B. L. Batista, J. M. O. Souza, S. S. De Souza, and F. Barbosa Jr., "Speciation of arsenic in rice and estimation of daily intake of different arsenic species by Brazilians through rice consumption," Journal of Hazardous Materials, vol. 191, no. 13, pp. 342-348, 2011.

[83] C.-Y. Tsai and S.-J. Jiang, "Microwave-assisted extraction and ion chromatography dynamic reaction cell inductively coupled plasma mass spectrometry for the speciation analysis of arsenic and selenium in cereals," Analytical Sciences, vol. 27, no. 3, pp. 271-276, 2011.

[84] V. Dufailly, M. Nicolas, J. Richoz-Payot, and E. Poitevin, "Validation of a method for arsenic speciation in food by ionchromatography-inductively coupled plasma/mass spectrometry after ultrasonic-assisted enzymatic extraction," Journal of AOAC International, vol. 94, pp. 947-958, 2011.

[85] M. D’Amato, F. Aureli, S. Ciardullo, A. Raggi, and F. Cubadda, "Arsenic speciation in wheat and wheat products using ultrasound- and microwave-assisted extraction and anion exchange chromatography-inductively coupled plasma mass spectrometry," Journal of Analytical Atomic Spectrometry, vol. 26, no. 1, pp. 207-213, 2011.

[86] C. Wu, Z. Ye, W. Shu, Y. Zhu, and M. Wong, "Arsenic accumulation and speciation in rice are affected by root aeration and variation of genotypes," The Journal of Experimental Botany, vol. 62, pp. 2889-2898, 2011.

[87] H. R. Hansen, A. Raab, A. H. Price et al., "Identification of tetramethylarsonium in rice grains with elevated arsenic 
content," Journal of Environmental Monitoring, vol. 13, pp. 3234, 2011.

[88] G. Raber, N. Stock, P. Hanel, M. Murko, J. Navratilova, and K. A. Fransesconi, "An improved HLPC-ICPMS method for determining inorganic arsenic in food: application to rice, wheat and tuna fish," Food Chemistry, vol. 134, pp. 524-532, 2012.

[89] T. Llorente-Mirandes, J. Calderon, J. F. Lopez-Sanchez, F. Centrich, and R. Rubio, "A fully validated method for the determination of arsenic species in rice and infant cereal products," Pure and Applied Chemistry, vol. 84, pp. 225-238, 2012.

[90] P. Alava, T. Van de Wile, F. Tack, and G. Du Laing, "Extensive grinding and pressurized extraction with water are key points for effective and species preserving extraction of arsenic from rice," Analytical Methods, vol. 4, pp. 1237-1243, 2012.

[91] J.-H. Huang, P. Fecher, G. Ilgen, K.-N. Hu, and J. Yang, "Speciation of arsenite and arsenate in rice grain-verification of nitric acid based extraction method and mass sample survey," Food Chemistry, vol. 130, pp. 453-459, 2012.

[92] A. A. Ammann, "Arsenic speciation by gradient anion exchange narrow bore ion chromatography and high resolution inductively coupled plasma mass spectrometry detection," Journal of Chromatography A, vol. 1217, no. 14, pp. 2111-2116, 2010.

[93] Codex Procedural Manual, Codex Alimentarius Commission, Rome, Italy, 19th edition, 2010.

[94] General Requirements for the Competence of Testing and Calibration Laboratories, International Organization for Standardization/International Electrotechnical Commission, Geneva, Switzerland, 1st edition, 1999.

[95] M. B. de la Calle, T. P. J. Linsinger, H. Emteborg, J. CharoudGot, and I. Verbist, "EUR 24314 EN," 2010, http://irmm.jrc.ec .europa.eu/EURLs/EURL_heavy_metals/interlaboratory_comparisons/imep-107/Pages/index.aspx.

[96] M. B. de la Calle, H. Emteborg, T. P. J. Linsinger et al., "Does the determination of inorganic arsenic in rice depend on the method?" Trends in Analytical Chemistry, vol. 30, pp. 641-651, 2011.

[97] ISO Guide 35: Reference Materials-General and Statistical Principles For Certification, International Organization for Standardization, Geneva, Switzerland, 2006.

[98] P. J. Lowthian and M. Thompson, "Bump-hunting for the proficiency tester-searching for multimodality," Analyst, vol. 127, no. 10, pp. 1359-1364, 2002.

[99] M. Thompson, "Recent trends in inter-laboratory precision at $\mathrm{ppb}$ and sub-ppb concentrations in relation to fitness for purpose criteria in proficiency testing," Analyst, vol. 125, no. 3, pp. 385-386, 2000.

[100] I. Baer, M. Baxter, V. Devesa et al., "Performance of laboratories in speciation analysis in seafood-case of methylmercury and inorganic arsenic," Food Control, vol. 22, no. 12, pp. 1928-1934, 2011.

[101] M. B. de la Calle, I. Baer, P. Robouch et al., "Is it possible to agree on a value for inorganic arsenic in food? The outcome of IMEP112," Analytical and Bioanalytical Chemistry, vol. 404, pp. 24752488, 2012.

[102] O. Butler, H. Evans, A. Fisher et al., "Atomic spectrometry updates: a 25-year retrospective," Journal of Analytical Atomic Spectrome-try, vol. 25, no. 10, pp. 1546-1566, 2010.

[103] C. F. Harrington, R. Clough, H. R. Hansen, S. J. Hill, S. A. Pergantis, and J. F. Tyson, "Atomic spectrometry update. Elemental speciation," Journal of Analytical Atomic Spectrometry, vol. 24, no. 8, pp. 999-1025, 2009.
[104] R. Clough, L. R. Drennan-Harris, C. F. Harrington, S. J. Hill, and J. F. Tyson, "Atomic spectrometry update. Elemental speciation," Journal of Analytical Atomic Spectrometry, vol. 27, pp. 1185-1224, 2012.

[105] E. Voigtman, "Limits of detection and decision. Parts 1, 2, 3, and 4," Spectrochimica Acta Part B, vol. 63, pp. 115-165, 2008.

[106] E. Voigtman and K. T. Abraham, "True detection limits in an experimental linearly heteroscedastic system. Parts 1 and 2," Spectrochimica Acta B, vol. 66, pp. 822-833, 2011.

[107] E. H. Evans, C. D. Palmer, and C. M. M. Smith, "Atomic spectrometry update. Advances in atomic spectrometry and related techniques," Journal of Analytical Atomic Spectrometry, vol. 27, pp. 909-927, 2012.

[108] C. H. Arnaud, "Cautionary tale for food analysis: inappropriate methods skewed results for arsenic in apple juice," Chemical \& Engineering News, vol. 90, no. 35, p. 32, 2012.

[109] P. Allain, L. Jaunault, Y. Mauras, J.-M. Mermet, and T. Delaporte, "Signal enhancement of elements due to the presence of carboncontaining compounds in inductively coupled plasma mass spectrometry," Analytical Chemistry, vol. 63, pp. 1497-1498, 1991.

[110] E. H. Larsen and S. Stürup, "Carbon-enhanced inductively coupled plasma mass spectrometric detection of arsenic and selenium and its application to arsenic speciation," Journal of Analytical Atomic Spectrometry, vol. 9, no. 10, pp. 1099-1105, 1994.

[111] K. Baba, T. Arao, Y. Maejima, E. Watanabe, H. Eun, and M. Ishizaka, "Arsenic speciation in rice and soil containing related compounds of chemical warfare agents," Analytical Chemistry, vol. 80, no. 15, pp. 5768-5775, 2008.

[112] Y. J. Zavala, R. Gerads, H. Gürleyük, and J. M. Duxbury, "Arsenic in rice: II. Arsenic speciation in USA grain and implications for human health," Environmental Science and Technology, vol. 42, no. 10, pp. 3861-3866, 2008.

[113] L. R. Harris, Studies in the atomic spectrometric determination of selenium, mercury, and rare earth elements [Ph.D. thesis], University of Massachusetts, Amherst, Mass, USA, 2012.

[114] B. Gammelgaard and O. Jøns, "Comparison of an ultrasonic nebulizer with a cross-flow nebulizer for selenium speciation by ion-chromatography and inductively coupled plasma mass spectrometry," Journal of Analytical Atomic Spectrometry, vol. 15, no. 5, pp. 499-505, 2000.

[115] L. L. Yu, T. A. Butler, and G. C. Turk, "Effect of valence state on ICP-OES value assignment of SRM 3103a arsenic spectrometric solution," Analytical Chemistry, vol. 78, no. 5, pp. 1651-1656, 2006.

[116] T. Narukawa, K. Chiba, T. Kuroiwa, and K. Inagaki, "Differences in sensitivity between As(iii) and As(v) measured by inductively coupled plasma spectrometry and the factors affecting the incoherent molecular formation (IMF) effect in the plasma," Journal of Analytical Atomic Spectrometry, vol. 25, no. 11, pp. 1682-1687, 2010.

[117] R. B. Khouzam, J. Szpunar, M. Holeman, and R. Lobinski, "Trace element speciation in food: state of the art of analytical techniques and methods," Pure and Applied Chemistry, vol. 84, pp. 169-179, 2012.

[118] A. A. Ammann, "Arsenic speciation analysis by ion chromatography-a critical review of principles and applications," American Journal of Analytical Chemistry, vol. 2, pp. 27-45, 2011.

[119] V. Dufailly, L. Noël, J. M. Frémy, D. Beauchemin, and T. Guérin, "Optimisation by experimental design of an IEC/ICP-MS speciation method for arsenic in seafood following microwave 
assisted extraction," Journal of Analytical Atomic Spectrometry, vol. 22, no. 9, pp. 1168-1173, 2007.

[120] B. K. Mandal, K. T. Suzuki, and K. Anzai, "Impact of arsenic in foodstuffs on the people living in the arsenic-affected areas of West Bengal, India," Journal of Environmental Science and Health A, vol. 42, no. 12, pp. 1741-1752, 2007.

[121] T. Narukawa and K. Chiba, "Heat-assisted aqueous extraction of rice flour for arsenic speciation analysis," Journal of Agricultural and Food Chemistry, vol. 58, no. 14, pp. 8183-8188, 2010.

[122] C. G. Yuan, G. B. Jiang, and B. He, "Evaluation of the extraction methods for arsenic speciation in rice straw, Oryza sativa L., and analysis by HPLC-HG-AFS," Journal of Analytical Atomic Spectrometry, vol. 20, no. 2, pp. 103-110, 2005.

[123] G.-X. Sun, T. Van de Wiele, P. Alava, F. Tack, and G. Du Laing, "Arsenic in cooked rice: effect of chemical, enzymatic and microbial processes on bioaccessibility and speciation in the human gastrointestinal tract," Environmental Pollution, vol. 162, pp. 241-246, 2012.

[124] J. M. Laparra, D. Vélez, R. Barberá, R. Farré, and R. Montoro, "Bioavailability of inorganic arsenic in cooked rice: practical aspects for human health risk assessments," Journal of Agricultural and Food Chemistry, vol. 53, no. 22, pp. 8829-8833, 2005.

[125] A. A. Meharg and F.-J. Zhao, "Arsenic in rice grain," in Arsenic \& Rice, p. 41, Springer, Dordrecht, Germany, 2012.

[126] A.-M. Carey, E. Lombi, E. Donner et al., "A review of recent developments in the speciation and location of arsenic and selenium in rice grain," Analytical and Bioanalytical Chemistry, vol. 402, pp. 3275-3286, 2012.

[127] A.-M. Carey, E. Lombi, E. Donner et al., "Erratum to: a review of recent developments in the speciation and location of arsenic and selenium in rice grain," Analytical and Bioanalytical Chemistry, vol. 402, no. 10, p. 3379, 2012.

[128] J. H. Huang, G. Ilgen, and P. Fecher, "Quantitative chemical extraction for arsenic speciation in rice grains," Journal of Analytical Atomic Spectrometry, vol. 25, no. 6, pp. 800-802, 2010.

[129] G. Turk, Personal Communication, Inorganic Chemical Metrology, Analytical Chemistry Division, National Institute of Standards and Technology, Gaithersburg, Md, USA, 2012.

[130] E. H. Larsen, "Method optimization and quality assurance in speciation analysis using high performance liquid chromatography with detection by inductively coupled plasma mass spectrometry," Spectrochimica Acta B, vol. 53, no. 2, pp. 253-265, 1998.

[131] A. Solà-Vázquez, J. M. Costa-Fernández, R. Pereiro, and A. Sanz-Medel, "Plasma-based mass spectrometry for simultaneous acquisition of elemental and molecular information," Analyst, vol. 136, no. 2, pp. 246-256, 2011.

[132] K. O. Amayo, A. Petursdottir, C. Newcombe et al., "Identification and quantification of arsenolipids using reversedphase HPLC coupled simultaneously to high-resolution ICPMS and high-resolution electrospray MS without species-specific standards," Analytical Chemistry, vol. 83, no. 9, pp. 3589-3595, 2011.

[133] D. A. Rogers, S. J. Ray, and G. M. Hieftje, "An electrospray/ inductively coupled plasma dual-source time-of-flight mass spectrometer for rapid metallomic and speciation analysis: part 1. Molecular channel characterization," Metallomics, vol. 2, no. 4, pp. 271-279, 2010.

[134] D. A. Rogers, S. J. Ray, and G. M. Hieftje, "An electrospray/ inductively coupled plasma dual-source time-of-flight mass spectrometer for rapid metallomic and speciation analysis: part 2. Atomic channel and dual-channel characterization," Metallomics, vol. 2, no. 4, pp. 280-288, 2010. 

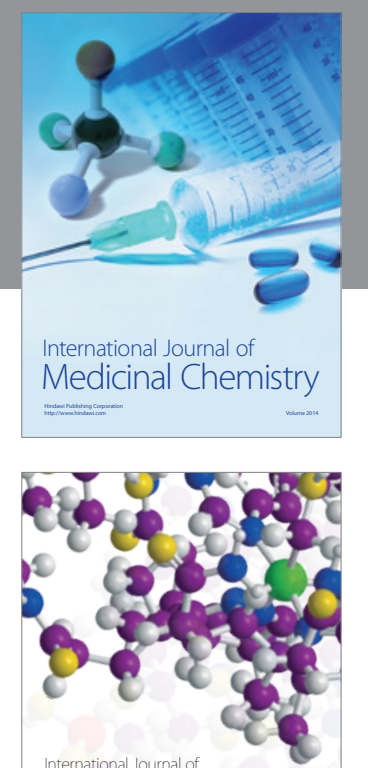

\section{Carbohydrate} Chemistry

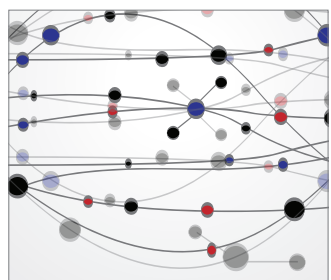

The Scientific World Journal
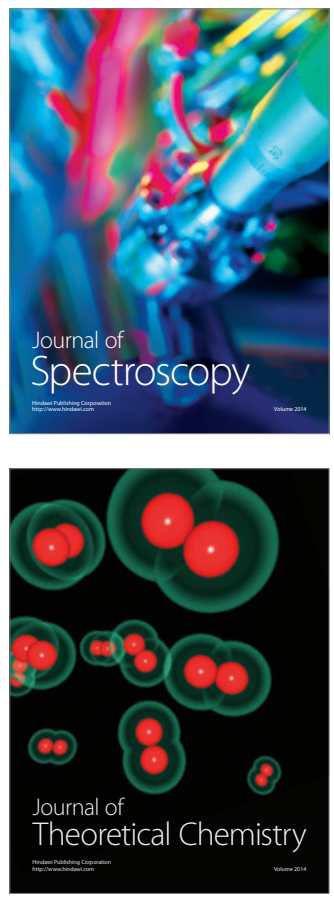
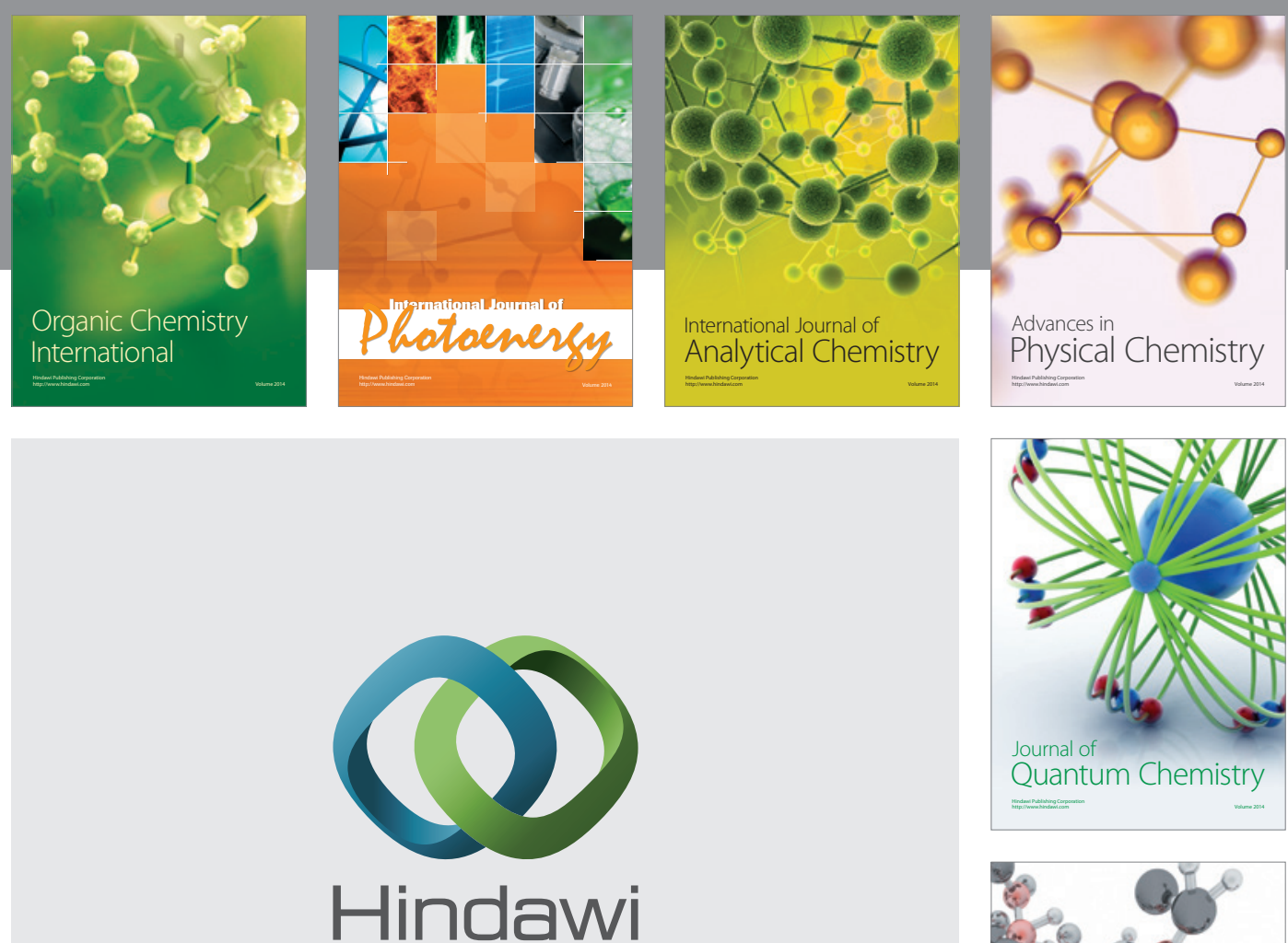

Submit your manuscripts at

http://www.hindawi.com

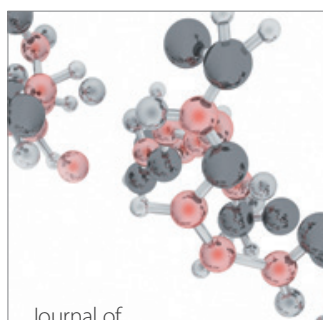

Analytical Methods

in Chemistry

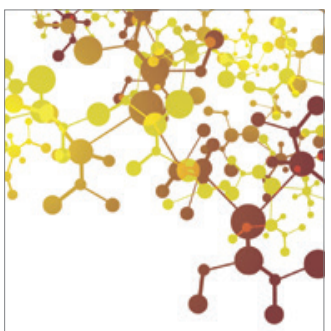

Journal of

Applied Chemistry

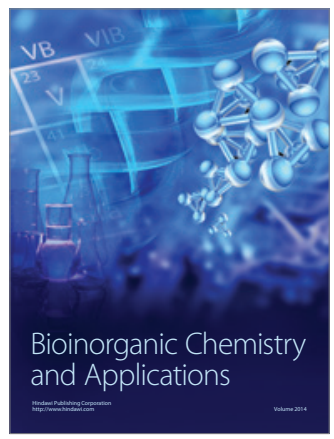

Inorganic Chemistry
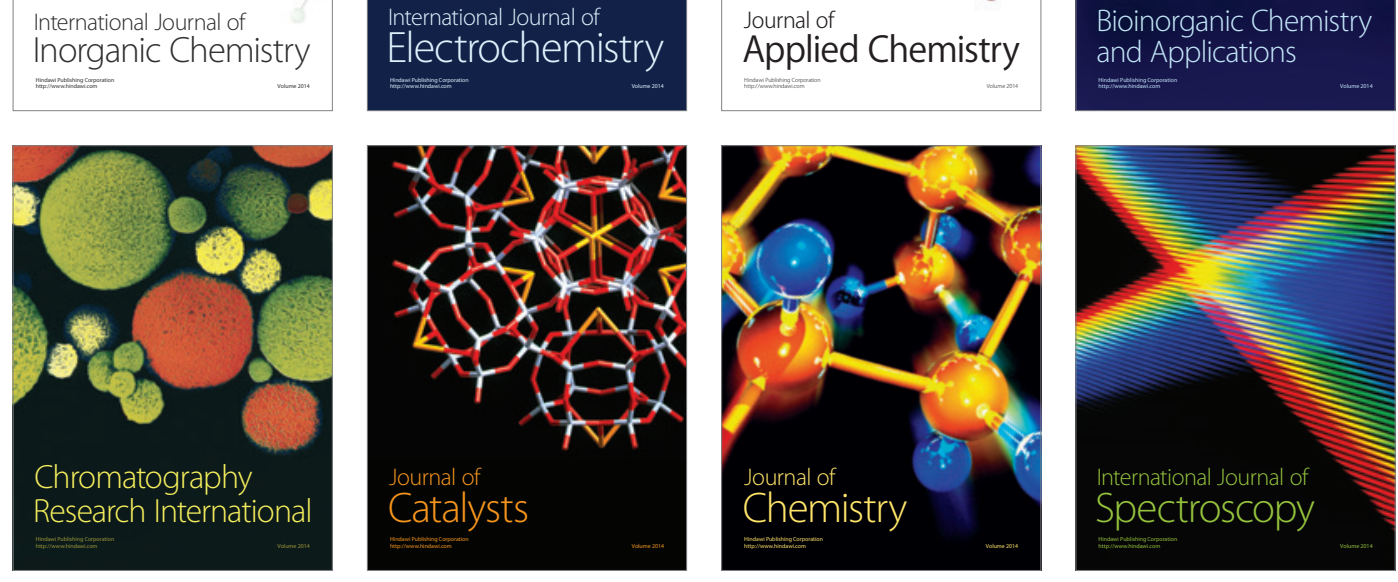